\title{
Design and Analysis of a Flexible, Reliable Deep Space Life Support System
}

\author{
Harry W. Jones ${ }^{1}$ \\ NASA Ames Research Center, Moffett Field, CA, 94035-0001
}

\begin{abstract}
This report describes a flexible, reliable, deep space life support system design approach that uses either storage or recycling or both together. The design goal is to provide the needed life support performance with the required ultra reliability for the minimum Equivalent System Mass (ESM). Recycling life support systems used with multiple redundancy can have sufficient reliability for deep space missions but they usually do not save mass compared to mixed storage and recycling systems. The best deep space life support system design uses water recycling with sufficient water storage to prevent loss of crew if recycling fails. Since the amount of water needed for crew survival is a small part of the total water requirement, the required amount of stored water is significantly less than the total to be consumed. Water recycling with water, oxygen, and carbon dioxide removal material storage can achieve the high reliability of full storage systems with only half the mass of full storage and with less mass than the highly redundant recycling systems needed to achieve acceptable reliability. Improved recycling systems with lower mass and higher reliability could perform better than systems using storage.
\end{abstract}

\section{Nomenclature}

$\begin{array}{ll}4 B M S & =\text { Four Bed Molecular Sieve } \\ B V A D & =\text { Baseline Values and Assumptions Document } \\ C E V & =\text { Crew Exploration Vehicle } \\ C M & =\text { Crew member } \\ D & =\text { Duration, days } \\ E C L S S & =\text { Environmental Control and Life Support Systems } \\ E S M & =\text { Equivalent System Mass } \\ F D I R & =\text { Fault detection, isolation, and repair } \\ H E F T & =\text { Human Exploration Framework Team } \\ H S I R & =\text { Human Systems Integration Requirements } \\ I S S & =\text { International Space Station } \\ K g & =\text { kilograms } \\ L E O & =\text { Low Earth Orbit } \\ \text { LiOH } & =\text { Lithium hydroxide } \\ L O C & =\text { Loss of Crew } \\ L O M & =\text { Loss of Mission (LOM) } \\ M T B F & =\text { Mean Time Before Failure } \\ N & =\text { Number of recycling processors } \\ N A S A & =\text { National Aeronautics and Space Administration } \\ N E O & =\text { Near Earth Object } \\ \operatorname{Pr} & =\text { Probability } \\ \operatorname{Pr}(\text { fail }) & =\text { Probability of failure } \\ \operatorname{Pr}(L O C) & =\text { Probability of LOC } \\ P S i a & =\text { Pounds per square inch absolute } \\ S P W E & =\text { Solid Polymer Water Electrolysis } \\ S S F & =\text { Space Station Freedom } \\ V C D & =\text { Vapor Compression Distillation } \\ & \end{array}$

${ }^{1}$ Systems Engineer, Bioengineering Branch, Mail Stop N239-8, AIAA Senior Member. 


\section{Introduction}

$\mathrm{T}$ HIS report describes the architecture design, analysis, and simulation of a flexible, reliable deep space life support system. The proposed life support system architecture achieves flexibility and reliability by using a mission duration dependent combination of storage and recycling to provide life support. Ultra reliability can be achieved by using storage, but the required launch mass is high. Recycling saves mass compared to storage, but recycling has such high mass and failure rates that systems using storage usually achieve the required reliability with less mass.

Other researchers have presented life support design approaches using storage and recycling with redundancy and computed the resulting Equivalent System Mass (ESM), but they did not specify or evaluate the system reliability. ${ }^{1,2}$ This work considers the system reliability and the resultant probability of Loss of Crew (LOC) for storage, recycling, and mixed storage and recycling configurations.

The deep space life support requirements, objectives, and design criteria are determined by the mission and are well understood. They include good performance, minimum life cycle cost, and ultra reliability to ensure crew safety. Deep space is the limitless region beyond the Earth-Moon system. Possible future deep space exploration objectives include Near Earth Objects (NEOs), which are asteroids in orbits similar to Earth's, Mars and its moons, and perhaps beyond to the asteroid belt and even Jupiter and its moons. The International Space Station (ISS) and a moon base would be suitable test beds for deep space and Mars life support.

There are two basic, familiar, and fundamentally different life support system architectures, open with Earth supplied material stored onboard, and closed with extensive material recycling. The possible use of planetary or insitu resources is an attractive addition. Open systems using Earth supply and storage are considered best for short missions that have low total life support material requirements, while closed recycling systems can save launch mass for long duration missions that have much greater total material consumption. The ISS originally had a ten year duration mission and uses recycling life support. As ISS illustrates, long duration missions are not necessarily in deep space, but deep space missions always have long duration because of their extended travel time.

Recycling is usually recommended for long duration missions because of the large amounts of water and oxygen consumed, but there is a design complication. Near space missions such as ISS have the potential to receive life support materials or spare parts quickly from Earth in the case of a failure, and the crew can return quickly if life support cannot be repaired. Deep space missions cannot get materials or parts quickly and the crew cannot return until the planets align. Deep space missions require much higher reliability than near space missions. The design complication is that open systems using materials sent from Earth and stored onboard are much more reliable than recycling systems using complicated mechanical components and chemical processes. The increasing distance and duration of further out deep space missions suggest both using recycling to reduce launch mass and using stored materials to increase reliability. The best system design uses both storage and recycling but is predominantly storage.

A flexible, reliable, deep space life support system design approach is adaptable, using a mix of stored and recycled materials, which could be supplemented by planetary or scavenged materials if available. Near space life support systems would typically use full storage for short missions and add recycling for missions longer than several months. Fully closed systems that use crop plants to grow food and recycle water and oxygen do not seem to be economical with current technology for even the longest missions. Deep space life support systems will use storage more than long duration near space systems, because the higher reliability requirement in deep space requires the use of storage. The best design is a hybrid architecture combining storage and recycling systems.

\section{Overview}

What should be the design architecture of the life support system for deep space missions? Trade studies performed over the last few decades suggest water and oxygen would be recycled using a system similar to the International Space Station (ISS) Environmental Control and Life Support System (ECLSS). A system similar to ISS ECLSS was tested with humans in a closed environment for ninety days during the Apollo era. Since then, life support research has focused on improving ECLSS subsystem technology for functions such as water purification or carbon dioxide removal.

Why was recycling always selected? Short missions to Low Earth Orbit (LEO) or in the Earth-Moon system, for instance Apollo and the space shuttle, provide the crew with water and oxygen launched from Earth and stored on board. But for long duration missions such as the ISS, the total required mass of water becomes very large and the cost of launching all this mass to LEO is prohibitive. Deep space missions using current rocket technology, and taking Hohmann trajectories to minimize propulsion energy and cost, necessarily have long durations. And the cost of transporting payload mass to its destination is much higher beyond LEO. Deep space missions were assumed to 
require recycling because of their long duration and the higher cost of mass per kilogram to reach objectives far beyond LEO.

The first human deep space mission such as exploring an NEO or Mars is in the future. It will present a new challenge to ECLSS because, unlike ISS, the crew cannot quickly obtain replacement parts or return to Earth if an ECLSS failure occurs. Deep space life support must be made ultra reliable by providing storage or redundant systems, as well as spare parts to repair failures.

It was long unquestioned that the life support system for deep space would recycle water and oxygen in a way similar to ISS and would provide higher reliability using redundancy. It was also usually assumed that the ISS ECLSS, although the model for deep space, would be extensively redesigned to reduce the mass of the system and its continuing material logistics supplies and to increase its intrinsic reliability.

Recent proposals challenge these assumptions. It has been suggested that deep space missions be conducted using the Orion Crew Exploration Vehicle (CEV) designed for short missions by providing large amounts of stored water and oxygen. It has been suggested that the ISS Node 3 containing its current ISS ECLSS be used in deep space. It has been suggested that stored materials be used instead of recycling to provide minimum survival needs, because of the lower intrinsic reliability of complex recycling systems and the consequent great cost and difficulty to achieve ultra reliability.

The best life support system design for deep space missions has become an open question after forty years. This report attempts an answer by investigating a flexible, reliable, deep space life support system design approach using storage and recycling systems or both.

\section{A. Content}

This report considers the following major design topics:

1. Life support material requirements

2. Life support reliability requirement

3. Storage systems

4. Redundant recycling systems

5. Partial mission duration storage with full recycling

6. Partial water storage and water recycling with full other storage

The different systems' ESM and reliability are compared and the best designs identified, as they depend on the mission duration. It was expected that pure storage life support would be best for brief near-Earth missions, that recycling with redundancy would save mass with adequate reliability on the longer shortest deep space missions such as NEO's, and that the farthest deep space missions such as Mars would need to use partial stores to increase reliability. As it turns out, redundant recycling cannot save mass and achieve the required reliability when compared with a combined water storage and recycling system, except for the longest missions beyond Mars.

\section{B. Results}

The report reiterates the following familiar results:

1. Recycling can save considerable mass on long missions.

2. Ultra reliability is needed for deep space missions.

The report confirms the following known but not always acknowledged points:

1. Ultra reliable recycling systems must be developed.

2. Developing ultra reliable recycling will be difficult, costly, and time-consuming.

The report finds the following unexpected results:

1. Recycling systems do not have low enough mass and failure rates to beat storage.

2. Material storage predominates in the lowest mass designs that meet reliability requirements.

3. For ultra reliability, storage must provide for all vital needs over the full mission duration.

4. Water beyond the survival minimum can be provided by redundant recycling.

5. Combined water storage and recycling can save half the mass of full storage systems.

Recycling will not fulfill its long anticipated role in deep space until its mass can be reduced and its reliability increased.

\section{Storage and recycling}

The optimum choice between, or combination of storage and recycling depends on the mission duration and reliability requirement. The amount of life support materials consumed by the crew grows directly with the mission duration. The fixed initial ESM of the recycling equipment must be paid for by the reduced mass of materials that 
otherwise would have been launched and stored. The ESM gained by recycling rather than Earth supply and storage increases with longer mission duration, so that recycling usually breaks even in ESM after several months. ${ }^{3}$ However, long duration missions in deep space require much higher reliability than missions to LEO or in the EarthMoon system. A deep space mission cannot be provided with life support materials or spare parts if a failure occurs and the crew cannot return quickly. Storage in simple tanks has intrinsically higher reliability than recycling using complex chemical processing machinery. Spare parts and redundancy are needed to increase the reliability of recycling, but they increase the ESM and delay the recycling breakeven date. Recent discussions within NASA have emphasized the need for ultra reliability and deemphasized the desirability of recycling and material closure ${ }^{4}$. Once we consider reliability, the long-obvious justification for concentrating on reducing the ESM of recycling equipment is less clear.

The best design for a deep space life support system provides adequately for the crew, over the mission duration, with the required probability of LOC, for the minimum ESM. If the life support requirements of materials per day and probability of LOC are fixed for the mission, the best design depends on the mission duration. The total amount of material increases directly with duration, so, considering ESM, longer duration favors recycling. A fixed probability of LOC over the mission duration requires a lower probability of LOC per day as the mission duration increases and a lower failure rate per day, so, considering reliability, longer duration favors higher reliability storage. This conflict creates a need to carefully consider the choice or mixture of storage and recycling.

Another consideration affects the conflicting goals of recycling closure and reliability as the mission duration increases. The daily life support requirements for food, oxygen, and water are not necessarily fixed. On longer missions, the crew needs exercise, increasing food and oxygen intake, and would benefit from showers, dishwashing, and laundry, greatly increasing water use. The increased material requirements per day for longer missions favor recycling, but the additional less necessary requirements may be provided with lower reliability or provide margin for more urgent requirements.

We will describe a flexible, reliable deep space life support system design approach using storage or recycling or both. It is assumed that all the food will be dehydrated with negligible water content. Fully hydrated food would add available water in a way similar to storage, and could be substituted for water storage. Some additional water will be produced from the metabolism of food. The mixed provision of life support material by storage and recycling can achieve ultra reliability with less mass than full storage.

\section{General requirements}

The deep space life support overall design requirement is, "Provide the required life support performance with ultra reliability at the minimum life cycle cost." The performance requirements are based on human physical needs and are well understood. Life support must establish a healthy environment by removing carbon dioxide and providing oxygen, water, and food. The water requirement has varied considerably, especially for hygiene and laundry, and loss of some hygiene water processing capacity would not be life threatening.

The life support design drivers controlling system sizing and reliability are the number of crew, the carbon dioxide, water, oxygen, and food mass requirements per crewmember per day, and the length of the mission. Multiplying the number of crew, the mass per crewmember per day, and the length of the mission in days gives the total mass of life support materials needed during the mission. The failure rate per day for life-threatening failures times the mission duration in days gives the probability of loss of crew due to life support failure. A constant failure rate per day is assumed. (For a discussion of this assumption see Appendix B: Exact failure probability calculations.)

We estimate the amount of oxygen required, carbon dioxide produced, and the minimum and more comfortable amounts of water. We then discuss the required reliability.

\section{A. Oxygen, carbon dioxide, and water quantity requirements}

The life support system functions include air revitalization (carbon dioxide removal, oxygen generation), and water reclamation (potable and hygiene water processing, urine reclamation). A summary of the minimum oxygen, carbon dioxide, and water processing rate requirements for a crewmember is given in Table 1, in $\mathrm{kg}$ per crewmember per day $(\mathrm{kg} / \mathrm{CM}-\mathrm{d})$. 
Table 1. Minimum life support system output products and input waste streams.

\begin{tabular}{|l|r|l|r|}
\hline \multicolumn{1}{|c|}{ Output products } & $\mathrm{kg} / \mathrm{CM}-\mathrm{d}$ & \multicolumn{1}{|c|}{ Input waste streams } & $\mathrm{kg} / \mathrm{CM}-\mathrm{d}$ \\
\hline Crew oxygen & 0.84 & Carbon dioxide & 1.00 \\
\hline Food solids & 0.62 & & \\
\hline Drinking and food water & 3.52 & Respiration and perspiration condensate & 2.28 \\
\hline Urine flush water & 0.50 & Urine and flush water & 2.00 \\
\hline Wash water & 1.29 & Used wash water & 1.29 \\
\hline Total system products & 6.77 & Total system inputs & 6.57 \\
\hline
\end{tabular}

These minimum requirements are based on space station analysis, except that showers, dish washing, and most crew hygiene water have been eliminated..$^{5-8}$ The waste streams include carbon dioxide and water produced from the dehydrated food by the crew metabolism.

A life support system using only initial supply and storage would provide oxygen, food, and water from storage. Carbon dioxide would be removed using lithium hydroxide $(\mathrm{LiOH})$ canisters. The crew could tolerate such a short supply of water for short missions and the cost of launching the life support mass would be relatively small.

The crew would benefit from more water on longer missions. Table 2 shows expanded water processing rate requirements per crewmember per day.

Table 2. Minimum plus expanded water system outputs and input waste streams.

\begin{tabular}{|l|r|l|r|}
\hline \multicolumn{1}{|c|}{ Output products } & \multicolumn{1}{c|}{$\mathrm{kg} / \mathrm{CM}-\mathrm{d}$} & \multicolumn{1}{c|}{ Input waste streams } & $\mathrm{kg} / \mathrm{CM}-\mathrm{d}$ \\
\hline Crew oxygen & 0.84 & Carbon dioxide & 1.00 \\
\hline Food solids & 0.62 & & \\
\hline Drinking and food water & 3.52 & Respiration and perspiration condensate & 2.28 \\
\hline Urine flush water & 0.50 & Urine and flush water & 2.00 \\
\hline Hygiene water & 12.27 & Used hygiene water & 12.27 \\
\hline Clothes washing water & 12.50 & Used clothes washing water & 11.90 \\
\hline & & Clothes dryer humidity & 0.60 \\
\hline Total system products & 30.25 & Total system inputs & 30.05 \\
\hline
\end{tabular}

The first four rows for oxygen, food, drinking water, and urine flush are identical to Table 1. The hygiene water is increased to include an additional $2.80 \mathrm{~kg} / \mathrm{CM}-\mathrm{d}$ of wash water, $2.73 \mathrm{~kg} / \mathrm{CM}-\mathrm{d}$ of shower water, and $5.45 \mathrm{~kg} / \mathrm{CM}-$ $\mathrm{d}$ of dish wash water. Clothes wash water is added. ${ }^{5-8}$ The cost of providing these materials would be very high for a long mission. A recycling life support system would generate most of the needed output products by recycling exhaled carbon dioxide, condensed respiration and perspiration water, urine and urine flush water, used hygiene water, used clothes washing water, and condensed clothes dryer humidity.

\section{B. Effects of lack of oxygen, carbon dioxide removal, and water}

Oxygen, carbon dioxide removal, and water are necessary to sustain life. The amount of each needed by an individual crewmember varies with body mass, food consumption, and especially with activity level and, for water, ambient temperature, but the individual's basic requirements of Table 1 must be met. Anoxia, low oxygen, can cause loss of consciousness and death within a few minutes.

A typical habitat volume at Earth normal atmosphere, contains $79 \mathrm{~kg}$ of nitrogen and $21 \mathrm{~kg}$ of oxygen. Three crewmembers will use $2.52 \mathrm{~kg}$ of oxygen per day, so with no additional oxygen, oxygen falls from 21 percent to 19 percent after one day, and 17 percent after two days, reaching the hypoxic boundary of impaired performance. ${ }^{6}$ However cabins of future spacecraft for human exploration may operate at pressures below Earth normal. ${ }^{9}$

The NASA Constellation Program Human Systems Integration Requirements (HSIR) specification calls for a nominal partial pressure of carbon dioxide less than 0.100 psia. ${ }^{10}$ For an Earth-normal atmosphere composition and pressure, $14.7 \mathrm{psia}$, this corresponds to 0.7 percent carbon dioxide by volume. This concentration is much higher than Earth normal, which is about 0.04 percent. Any level more than 0.2 percent is usually noticeable unless gradual adjustment has occurred. Adaptation to sustained carbon dioxide levels of up 2 percent is possible without adverse effects. Above 2 percent by volume, carbon dioxide causes headaches and hyperventilation. At 3 percent, it causes breathing problems, and at 6 percent, hearing and vision are affected. ${ }^{11,12}$ 
Tables 1 and 2 indicate that one crewmember produces $1.0 \mathrm{~kg}$ of carbon dioxide per day. A typical habitat volume contains about $100 \mathrm{~kg}$ of Earth normal atmosphere. Without carbon dioxide removal, three crewmembers will accumulate 3 percent of carbon dioxide in one day and 6 percent in two days, causing very serious problems. ${ }^{13}$

Lack of water is less acute but also extremely serious. Dehydration can cause nausea, cramps, lightheadedness, confusion, weakness, coma, and death. At $70 \mathrm{~F}$, remaining quiet, a person might possibly live ten days without water. However, earthquake victims trapped without water typically do not survive more than three days. The absolute bare minimum water loss possible for person resting at a cool temperature is about $1.3 \mathrm{~kg}$ per day. ${ }^{14,15}$ This is about one-fourth the specified requirement of $5.31 \mathrm{~kg}$ in Table 1. Death occurs when water having about 20 percent of body weight is lost. ${ }^{14,15}$ Drinking and food preparation water must be ultra reliable, with one or two days maximum unavailability. Urine flush water, hygiene water, and clothes wash water are far less important.

\section{Probability of loss of crew, $\operatorname{Pr}(\mathrm{LOC})$, requirement}

Given the life support performance needed, the other major requirement is the reliability of that performance, expressed as the probability of loss of crew, $\operatorname{Pr}(\mathrm{LOC})$. A reasonable $\operatorname{Pr}(\mathrm{LOC})$ for an entire deep space mission, acknowledged to be high risk, might be 1 in 100 . The life support system $\operatorname{Pr}(\mathrm{LOC})$ must then be roughly an order of magnitude lower, 1 in 1,000. LOC can be caused by a zero oxygen level for a few minutes, no added oxygen for about three days, no carbon dioxide removal for about two days, or no drinking and food preparation water for about two days. We will assume that the $\operatorname{Pr}(\mathrm{LOC})$ must be less than 1 in 1,000 for all mission durations.

Since we assume that the probability of LOC will be a certain fixed number for all mission durations, the daily failure rate of the life support system must decrease directly with the mission duration. Design to meet the required $\operatorname{Pr}(\mathrm{LOC})$ will be easier at shorter durations and more difficult at longer durations. The best life support design achieves the required $\operatorname{Pr}(\mathrm{LOC})$ at minimum ESM.

\section{Life support storage equivalent system mass, ESM}

Storage life support systems provide all the needed materials from Earth without recycling and they store or discard all the waste. The cost of stored supplies is proportional to the mass of life support supplies needed. The materials provided include oxygen, water, and lithium hydroxide $(\mathrm{LiOH})$ to remove carbon dioxide from the cabin atmosphere. Additional mass is required for oxygen and water tanks and for $\mathrm{LiOH}$ packaging.

A crewmember's daily requirements for oxygen and water were shown in Table 1 . The oxygen and water require additional mass for storage tanks. Reasonable estimates are $0.4 \mathrm{~kg}$ of tankage per $\mathrm{kg}$ of oxygen ${ }^{11}$ and $0.2 \mathrm{~kg}$ of tankage per kg of water. ${ }^{16}$ About $2 \mathrm{~kg}$ of $\mathrm{LiOH}$ is required to remove the $1 \mathrm{~kg}$ of carbon dioxide per crewmember per day. ${ }^{17}$ The shuttle canister weighs $7 \mathrm{~kg}$ and is rated at 4 crewmember-days, which gives $1.75 \mathrm{~kg} / \mathrm{CM}-\mathrm{d}$.

The total daily material needs for oxygen, water, their tanks, $\mathrm{LiOH}$, and its packaging are shown in Table 3 .

Table 3. Storage life support ESM.

\begin{tabular}{|l|r|}
\hline & $\mathrm{kg} / \mathrm{CM}-\mathrm{d}$ \\
\hline Oxygen & 0.84 \\
\hline Oxygen tankage & 0.34 \\
\hline Water & 5.31 \\
\hline Water tankage & 1.06 \\
\hline LiOH and packaging & 1.75 \\
\hline Total & 9.30 \\
\hline
\end{tabular}

Oxygen, water, and carbon dioxide removal can be provided for $9.30 \mathrm{~kg} / \mathrm{CM}-\mathrm{d}$. 


\section{Life support recycling system}

Figure 1 shows the block diagram of a typical life support system using recycling.

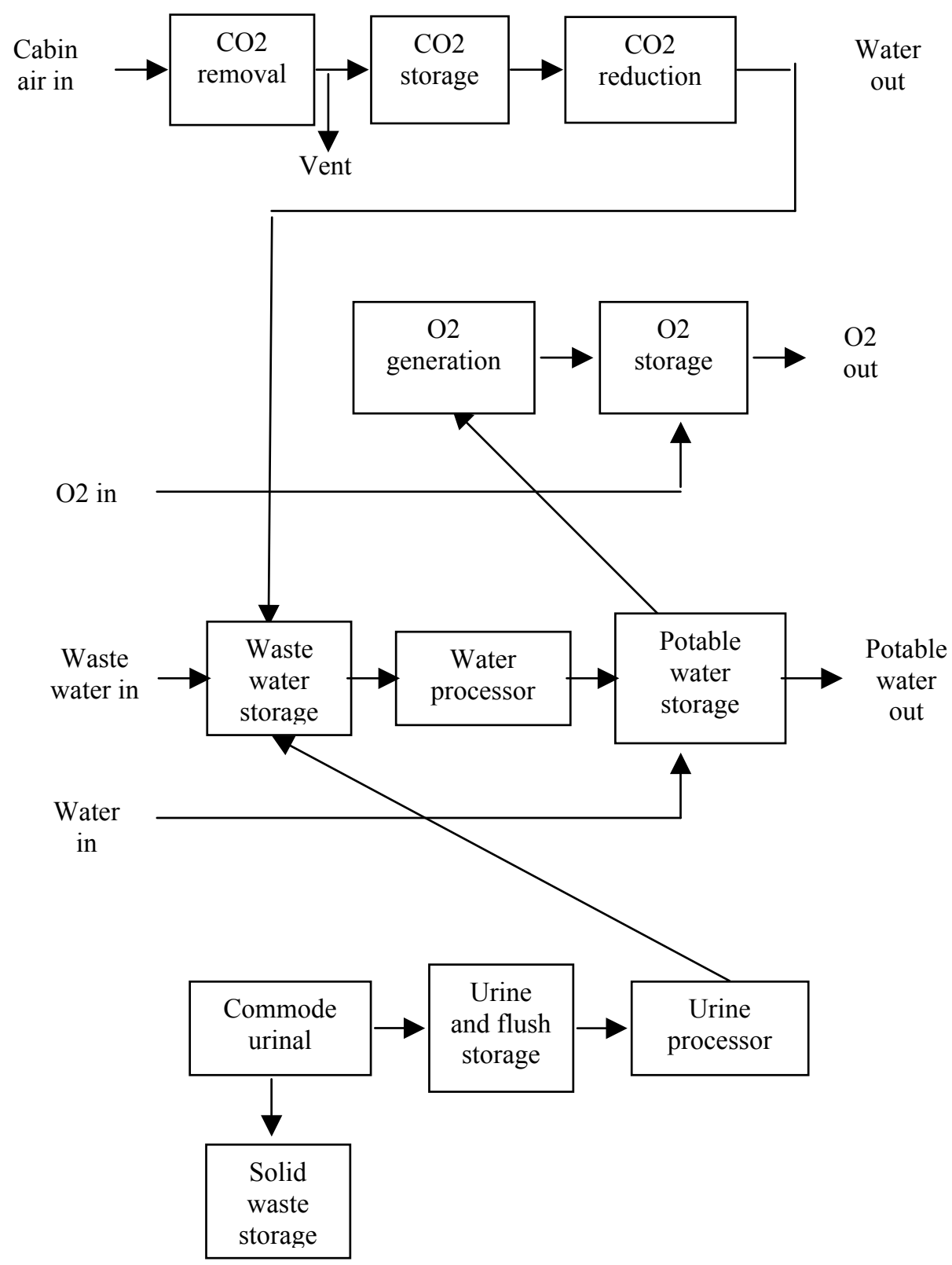

Figure 1. The standard recycling life support system design.

The system in Figure 1 is essentially identical to the recycling International Space Station (ISS) life support system. ${ }^{18-20}$ A similar recycling architecture has been used since the 1960's. Recycling systems do require some storage of oxygen and potable water, but much less than the total mission consumption.

The standard recycling life support system has systems that deal with carbon dioxide, oxygen, wastewater, and urine and flush water. The ISS life support technologies are listed in Table 4. 
Table 4. ISS technologies.

\begin{tabular}{|l|l|}
\hline Carbon dioxide removal & Four Bed Molecular Sieve (4BMS) \\
\hline Carbon dioxide reduction & Sabatier \\
\hline Oxygen storage & High pressure tanks \\
\hline Oxygen generation & Solid Polymer Water Electrolysis (SPWE) \\
\hline Water storage & Stainless steel tanks with metal bellows \\
\hline Water processing & Multifiltration \\
\hline Urine processing & Vapor Compression Distillation (VCD) \\
\hline
\end{tabular}

The ISS technologies were originally selected for Space Station Freedom (SSF). ${ }^{21}$ Carbon dioxide is removed using a Four Bed Molecular Sieve (4BMS) and stored. It is reduced to water and methane by a Sabatier processor. Since the crew produces water as well as carbon dioxide by metabolizing food using the atmospheric oxygen, recycling all the crew's consumed oxygen also requires generating oxygen from water. Oxygen is stored in high pressure tanks. Oxygen is generated by the Solid Polymer Water Electrolysis (SPWE) of water. The oxygen is usually vented directly to the cabin, but an additional stored reserve would be needed in case of a loss of cabin pressure. Pressure tanks could be used and refilled during the mission. The hydrogen produced by oxygen electrolysis is used by the Sabatier for carbon dioxide reduction. The methane produced by the Sabatier is vented, but could be used for propulsion.

The hygiene and laundry water is stored and processed to potable using multifiltration. Not shown are the condensing heat exchangers that cool the atmosphere and remove humidity that is also recycled by multifiltration. Urine and flush water are purified by Vapor Compression Distillation (VCD) before being added to the other wastewater.

\section{Life support recycling equipment equivalent system mass}

The system mass is frequently used to compare life support systems. It has been generalized as Equivalent System Mass (ESM), which includes the mass of the hardware, its spare parts and operating materials, the mass of the power and cooling systems required to support the system, and even the structural mass required to provided the enclosed pressurized volume to house the system. A life support system using storage will have the total mass increase rapidly with longer mission duration. A recycling system will have a large initial mass of hardware and supporting equipment but only a slowly increasing mass of spare parts and materials. After a certain mission duration called the ESM breakeven date, the mass of a recycling system will be less than that of a resupply system. The breakeven dates for air and water recycling systems are typically several months, with water recycling breaking even first.

To estimate the ESM of future deep space life support systems, we use the ESM of the International Space Station (ISS) Environmental Control and Life Support System (ECLSS). The ESM is obtained by summing the mass, volume, power, and cooling requirements of the individual ECLSS components and computing the equivalent mass using Mars deep space transit mass equivalents.

The functions and technologies of the ISS ECLSS are listed in Table 4. The mass, volume, power, and cooling are from Carrasquillo, Reuter and Philistine, $1997^{21}$, except for the Sabatier, which is from Eckart, $1996 .{ }^{17}$

ESM is based on the system mass, $\mathbf{m}$, volume, $\mathbf{v}$, power, $\mathbf{p}$, cooling, $\mathbf{c}$, logistics mass per year, $\mathbf{l}$, and $\mathbf{d}$, the mission duration. ESM determines the launch mass and cost.

$\operatorname{ESM}(\mathbf{m}, \mathbf{v}, \mathbf{p}, \mathbf{c}, \mathbf{l}, \mathbf{d})=\mathbf{m}+\mathbf{v} * \operatorname{me}(\mathbf{v})+\mathbf{p} * \operatorname{me}(\mathbf{p})+\mathbf{c} * \operatorname{me}(\mathbf{c})+\mathbf{l} * \mathbf{d}$

me(v) is the mass equivalent of volume, etc. ${ }^{23}$

\section{A. ISS ECLSS ESM}

The ESM of the ISS recycling ECLSS is shown in Table 5. The ESM is adjusted to the number of crewmembers supported. The mass equivalents are for a Mars deep space transit mission. ${ }^{11}$ 
Table 5. ISS ECLSS ESM.

\begin{tabular}{|c|c|c|c|c|c|c|c|c|}
\hline Function & & $\begin{array}{c}\# \\
\text { CM }\end{array}$ & $\begin{array}{c}\text { mass, } \\
\mathrm{kg}\end{array}$ & $\begin{array}{l}\text { volume, } \\
\text { m3 }\end{array}$ & $\begin{array}{l}\text { power, } \\
\mathrm{kW}\end{array}$ & $\begin{array}{c}\text { cooling, } \\
\mathrm{kW}\end{array}$ & $\begin{array}{c}\text { ESM, } \\
\mathrm{kg} / \mathrm{CM}\end{array}$ & $\begin{array}{l}\text { logistics, } \\
\mathrm{kg} / \mathrm{CM}-\mathrm{d}\end{array}$ \\
\hline $\begin{array}{l}\text { Carbon dioxide } \\
\text { removal }\end{array}$ & 4BMS & 4 & 201 & 0.39 & 0.86 & 0.86 & 135 & 0.00 \\
\hline $\begin{array}{l}\text { Carbon dioxide } \\
\text { reduction }\end{array}$ & Sabatier & 4 & 18 & 0.75 & 0.05 & 0.27 & 52 & 0.00 \\
\hline $\begin{array}{l}\text { Oxygen } \\
\text { provision }\end{array}$ & SPWE & 7 & 113 & 0.14 & 1.47 & 1.47 & 83 & 0.00 \\
\hline Oxygen storage & tank & 4 & 1,088 & 0.00 & 0.00 & 0.00 & 272 & 0.00 \\
\hline Urine processing & $\mathrm{VCD}$ & 8 & 128 & 0.37 & 0.09 & 0.09 & 29 & 0.06 \\
\hline Water provision & $\begin{array}{l}\text { Multi- } \\
\text { filtration }\end{array}$ & 10 & 476 & 2.25 & 0.30 & 0.30 & 105 & 0.13 \\
\hline Water storage & tank & 4 & 106 & 0.52 & 0.00 & 0.00 & 54 & 0.00 \\
\hline & totals & & & & & & 730 & 0.20 \\
\hline & $\begin{array}{l}\text { mass } \\
\text { equivalents }\end{array}$ & & 1 & 215.5 & 237 & 60 & & \\
\hline & units & & $\mathrm{kg} / \mathrm{kg}$ & $\mathrm{kg} / \mathrm{m}^{3}$ & $\mathrm{~kg} / \mathrm{kW}$ & $\mathrm{kg} / \mathrm{kW}$ & & \\
\hline
\end{tabular}

The ISS ECLSS ESM is $730 \mathrm{~kg} / \mathrm{CM}$. The corresponding logistics support is $0.20 \mathrm{~kg} / \mathrm{CM}$-d. The ECLSS logistics do not include oxygen and water from the shuttle, since these are to be provided by recycling. The ECLSS logistics also do not include yearly replacement of the oxygen tanks. Nearly half (45\%) of the initial ESM even in a recycling system is used for oxygen and water storage.

\section{B. ESM breakeven date}

Recycling breaks even in ESM when the mission duration, D, is sufficiently long that the ESM of recycling becomes less than the mass of an all storage system. Using the ISS ECLSS component based estimate of ESM, this occurs when $730 \mathrm{~kg}+0.20 \mathrm{~kg} /$ day $* \mathrm{D}$ days $<9.30 \mathrm{~kg} /$ day $* \mathrm{D}$ days. The breakeven mission duration is 80 days. It would be roughly half that (44 days) if the storage used with ISS ECLSS recycling was not included in ESM.

\section{Life support storage reliability}

Water and oxygen storage tanks and $\mathrm{LiOH}$ canisters are simple and have high reliability. Using multiple containers and providing spares can easily achieve ultra reliability. Table 6 shows storage component failure rate per day, Mean Time Before Failure (MTBF), and probability of failure, $\operatorname{Pr}($ fail), in 1,000 days.

Table 6. Storage failure rates per day, MTBF, and $\operatorname{Pr}($ fail).

\begin{tabular}{|l|r|r|r|r|r|}
\hline $\begin{array}{c}\text { Storage } \\
\text { component }\end{array}$ & $\begin{array}{c}\text { Failure rate } \\
\text { per day }\end{array}$ & $\begin{array}{c}\text { MTBF, } \\
\text { days }\end{array}$ & $\begin{array}{c}\text { Pr(fail) in } \\
1,000 \text { days }\end{array}$ & $\begin{array}{c}\text { Pr(fail) in 1,000 days } \\
\text { with full spares }\end{array}$ & $\begin{array}{c}\text { Pr(fail) in 1,000 days } \\
\text { with 10\% spares }\end{array}$ \\
\hline Water tank & $2.40 \mathrm{E}-07$ & $4,166,667$ & $2.40 \mathrm{E}-04$ & $5.76 \mathrm{E}-08$ & $3.16 \mathrm{E}-06$ \\
\hline Oxygen tank & $1.00 \mathrm{E}-06$ & $1,000,000$ & $1.00 \mathrm{E}-03$ & $1.00 \mathrm{E}-06$ & $5.47 \mathrm{E}-05$ \\
\hline LiOH canister & $3.60 \mathrm{E}-05$ & 27,792 & $3.60 \mathrm{E}-02$ & $0.00 \mathrm{E}+00$ & $4.08 \mathrm{E}-17$ \\
\hline Total & $3.72 \mathrm{E}-05$ & 26,866 & $3.72 \mathrm{E}-02$ & $1.06 \mathrm{E}-06$ & $5.78 \mathrm{E}-05$ \\
\hline
\end{tabular}

The failure rates are estimated from Yakut and Barker, $1968 .{ }^{23}$ The MTBF is the inverse of the failure rate and is 26,866 days, about 74 years. This seems good, but the overall $\operatorname{Pr}$ (fail) for 1,000 days is $0.0372,37.2$ times the maximum $\operatorname{Pr}(\mathrm{LOC})$ of 0.001 . The $\operatorname{Pr}(\mathrm{LOC})$ is the probability that the one water tank or the one oxygen tank or one of the 1,000 LiOH canisters will fail, leaving the crew with insufficient life support.

\section{A. Increasing storage reliability with spares}

The most likely failure is a $\mathrm{LiOH}$ canister. A new one is used every day and the daily failure rate is the estimated probability that one will fail. We can improve reliability using spares. If full redundancy was provided, with two full 
water tanks, two full oxygen tanks and twice the number of LiOH canisters, reliability would be greatly increased. If we provide 2,000 $\mathrm{LiOH}$ canisters when 1,000 are needed, the probability that 1,001 will fail is vanishingly small. The overall probability of LOC is three orders of magnitude less than the requirement. However, the already large mass is doubled.

It is more efficient to divide the water and oxygen tanks into ten tanks each and provide one spare for both. A loss of crew still requires two tank failures. Similarly the 1,000 LiOH canisters are provided with 100 spares, and 101 must fail to cause loss of crew. Ten percent spares are used because five percent was not sufficient to achieve the needed reliability.

The probability that ten tanks with one spare will fail is much higher than the probability two tanks will fail, since there are $11 * 10=110$ different pairs of tanks that can fail. The exact failure probability calculation uses the binomial distribution, following calculations from Jones $2008 .{ }^{24}$ Using ten percent spares, the total $\operatorname{Pr}($ fail) in 1,000 days is reduced to $5.78 * 10^{-5}$, still more than ten times lower than the requirement. $\operatorname{The} \operatorname{Pr}(\mathrm{LOC})$ is nearly all due to the oxygen tanks and additional spare would reduce it two orders of magnitude.

Life support using storage can easily achieve ultra reliability using spares with only a reasonable mass increase. The effectiveness of storage spares depends on the assumption that common cause failures will not occur. The simplicity and long history of the storage tank and canister technologies make this seem plausible. Life support systems contain many more components (connectors, fans, pumps, etc) than the basic subsystems and assemblies used in these calculations. Although reliability computations would be improved, this auxiliary hardware is generally common to all architectures discussed.

\section{$X$. Life support recycling reliability}

The failure rates for the active recycling processors in Figure 1 and the ISS technologies in Table 4 were computed in Appendix A using the schematics, parts lists, and component reliabilities in Yakut and Barker, 1968. ${ }^{25}$ Table 7 shows recycling system processors' failure rate per day and Mean Time Before Failure (MTBF).

Table 7. Recycling failure rates per day and MTBF's.

\begin{tabular}{|c|c|c|c|c|c|c|}
\hline Function & Processor & $\begin{array}{l}\text { Failure } \\
\text { rate per } \\
\text { day }\end{array}$ & $\begin{array}{c}\text { MTBF, } \\
\text { days }\end{array}$ & $\begin{array}{l}\text { LOC one } \\
\text { tenth failure } \\
\text { rate }\end{array}$ & $\begin{array}{c}\text { LOC ten } \\
\text { times } \\
\text { MTBF, } \\
\text { days }\end{array}$ & $\begin{array}{l}\text { Approximate } \\
\operatorname{Pr}(\text { LOC }) \text { in } \\
1,000 \text { days }\end{array}$ \\
\hline $\begin{array}{l}\text { Carbon dioxide } \\
\text { removal }\end{array}$ & $\begin{array}{l}\text { Four Bed Molecular } \\
\text { Sieve (4BMS) }\end{array}$ & $2.99 \mathrm{E}-03$ & 335 & $2.99 \mathrm{E}-04$ & 3,349 & 0.299 \\
\hline $\begin{array}{l}\text { Carbon dioxide } \\
\text { reduction }\end{array}$ & Sabatier & $2.74 \mathrm{E}-03$ & 365 & $2.74 \mathrm{E}-04$ & 3,651 & 0.274 \\
\hline Oxygen generation & $\begin{array}{l}\text { Solid Polymer } \\
\text { Water Electrolysis } \\
\text { (SPWE) }\end{array}$ & $2.10 \mathrm{E}-03$ & 476 & $2.10 \mathrm{E}-04$ & 4,761 & 0.210 \\
\hline Water processing & Multifiltration & $4.39 \mathrm{E}-03$ & 228 & $4.39 \mathrm{E}-04$ & 2,277 & 0.439 \\
\hline Urine processing & $\begin{array}{l}\text { Vapor Compression } \\
\text { Distillation (VCD) }\end{array}$ & $3.71 \mathrm{E}-03$ & 269 & $3.71 \mathrm{E}-04$ & 2,694 & 0.371 \\
\hline & Totals & $1.59 \mathrm{E}-02$ & 63 & $1.59 \mathrm{E}-03$ & 628 & 0.860 \\
\hline
\end{tabular}

Recycling systems are complex and have much lower reliability than simple storage systems. The processor failure rates range from 0.21 to 0.44 percent per day, and the total of the five processors failure rates is 1.59 percent per day. The corresponding MTBF's, which are the inverse of the failure rate, range from 228 to 476 days, and the overall MTBF is only 63 days. These rates and MTBF's seem to be the right order of magnitude for the ISS technologies, as they suggest one life support failure every two months rather than every two weeks or every two years. (The calculations of Table 7 use a standard approximation described in Appendix B. The approximate $\operatorname{Pr}(\mathrm{LOC})$ 's in 1,000 days are up to 20 percent too high. See Appendix B for exact failure probability calculations.)

For deep space missions, we are less concerned with recurring failures and repairs than with unrecoverable failures than can cause loss of crew. Space station provides replacement units for on orbit replacement of key subsystems, and a new deep space system would be designed to be repaired and would provide spares for extensive replacement of valves, pumps, sensors, and other components that are likely to fail. We assume that providing extensive replacement units and spare parts can reduce the failure rate by a factor of ten. If no common cause failures occur, providing spares could provide much higher expected reliability, but common cause failures are 
typically ten percent of all failures, which would set a factor of ten bound to the failure rate reduction than can be obtained using spares.

We assume that unrepairable failures causing loss of crew (LOC) are one tenth of the total failure rate. The corresponding LOC failure rates and MTBF's are also given in Table 7. The probability of LOC, $\operatorname{Pr}(\mathrm{LOC})$, in 1,000 days for each system is 1,000 times its LOC failure rate, and ranges from 21 to 44 percent. Considering there are five life support processors, the $\operatorname{Pr}(\mathrm{LOC})$ approaches certainty in 1,000 days. In addition to providing spares and repairing the life support system, something more must be done to achieve acceptable $\operatorname{Pr}(\mathrm{LOC})$ for long missions.

\section{Comparison of storage and recycling ESM}

We consider simple storage with one water tank, one oxygen tank, and 1,000 LiOH canisters. We also investigate storage with ten percent spares, corresponding to 10 smaller water tanks with one spare, 10 smaller oxygen tanks with one spare, and 1,000 LiOH canisters with 100 spares. The ESM of storage is $9.30 * \mathrm{D} \mathrm{kg} / \mathrm{CM}$, where $\mathrm{D}$ is the mission duration in days, and the ESM increases to $10.23 * \mathrm{D} \mathrm{kg} / \mathrm{CM}$ with ten percent spares. These two storage ESM's are plotted in Figure 1, going up and right from the origin.

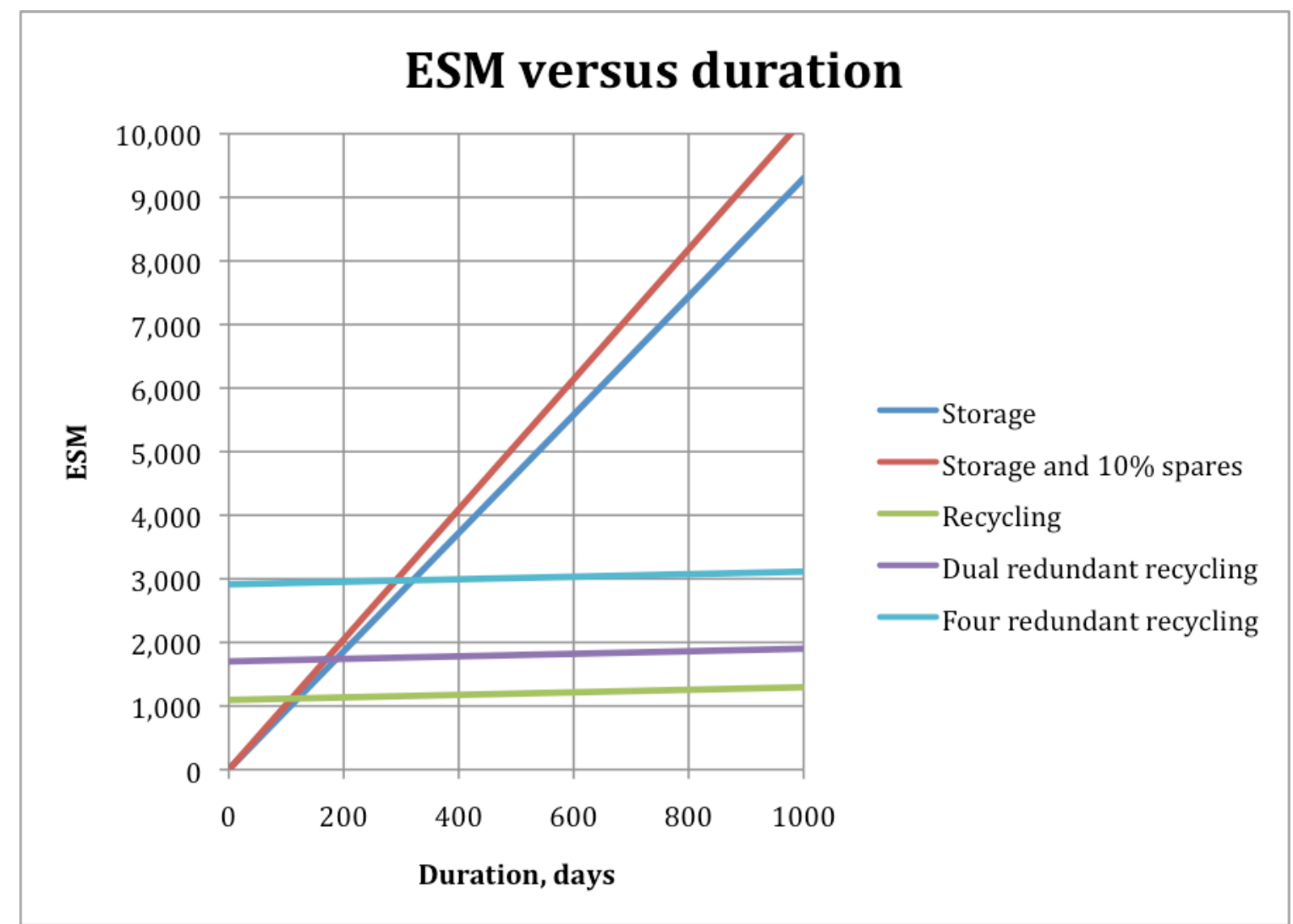

Figure 1. Storage and recycling ESM.

We consider a recycling system in which each subsystem has spares that increase the fixed ESM by fifty percent and cut the failure rate by one order of magnitude, as discussed previously. The ESM of a recycling system with fifty percent spares by mass is $1,095 \mathrm{~kg} / \mathrm{CM}+0.20 * \mathrm{D} \mathrm{kg} / \mathrm{CM}$, where $\mathrm{D}$ is the mission duration in days. (From Table $5,730 * 1.5=1,095$.)

We also consider recycling systems where each active subsystem has $\mathrm{N}$ redundant copies, one operating and $\mathrm{N}-1$ spares. We will assume that we have available several carbon dioxide removal, carbon dioxide reduction, oxygen generation, water processing, and urine processing recycling technologies, and that all are different so that there are no internal common cause failures. Each technology has a fixed initial ESM, a daily logistics and material resupply mass, and a failure rate per day. For simplicity, we assume that all the different recycling processors for the same function have the same ESM, daily logistics mass, and failure rate. We assume that the oxygen and water storage tanks used in recycling are highly reliable and do not require spares. 
The ESM of recycling with $\mathrm{N}-1$ redundant non-operating spares is $1,095 \mathrm{~kg} / \mathrm{CM}+606 *(\mathrm{~N}-1) \mathrm{kg} / \mathrm{CM}+0.20$ $* \mathrm{D} \mathrm{kg} / \mathrm{CM}$. (From Table 5, $(730-272-54) * 1.5=606$.) The recycling ESM's are plotted in Figure 1, for a single recycling system, $\mathrm{N}=2$ dual redundancy, and $\mathrm{N}=4$ redundancy. The breakevens with storage and $10 \%$ spares occur at about 120 days for a single system, 180 days for $\mathrm{N}=2$ redundancy, and 300 days for $\mathrm{N}=4$ redundancy.

\section{Comparison of storage and recycling $\operatorname{Pr}(\mathrm{LOC})$}

The $\operatorname{Pr}(\mathrm{LOC})$ of storage with no spares is the failure rate per day times the number of days, $3.72 * 10^{-5} * \mathrm{D}$, from Table 6. The $\operatorname{Pr}(\mathrm{LOC})$ of storage with $10 \%$ spares is computed using the binomial distribution, as mentioned. The value of the $\operatorname{Pr}(\mathrm{LOC})$ is $5.7810^{-5}$ at 1,000 days, as shown in Table 6. The storage $\operatorname{Pr}(\mathrm{LOC})$ 's are plotted in Figure 2. Storage with no spares fails to meet the required $\operatorname{Pr}(\mathrm{LOC})$ of $10^{-3}$ after only 27 days. Storage with ten percent spares has a $\operatorname{Pr}(\mathrm{LOC})$ more than one order of magnitude better than the requirement at 1,000 days.

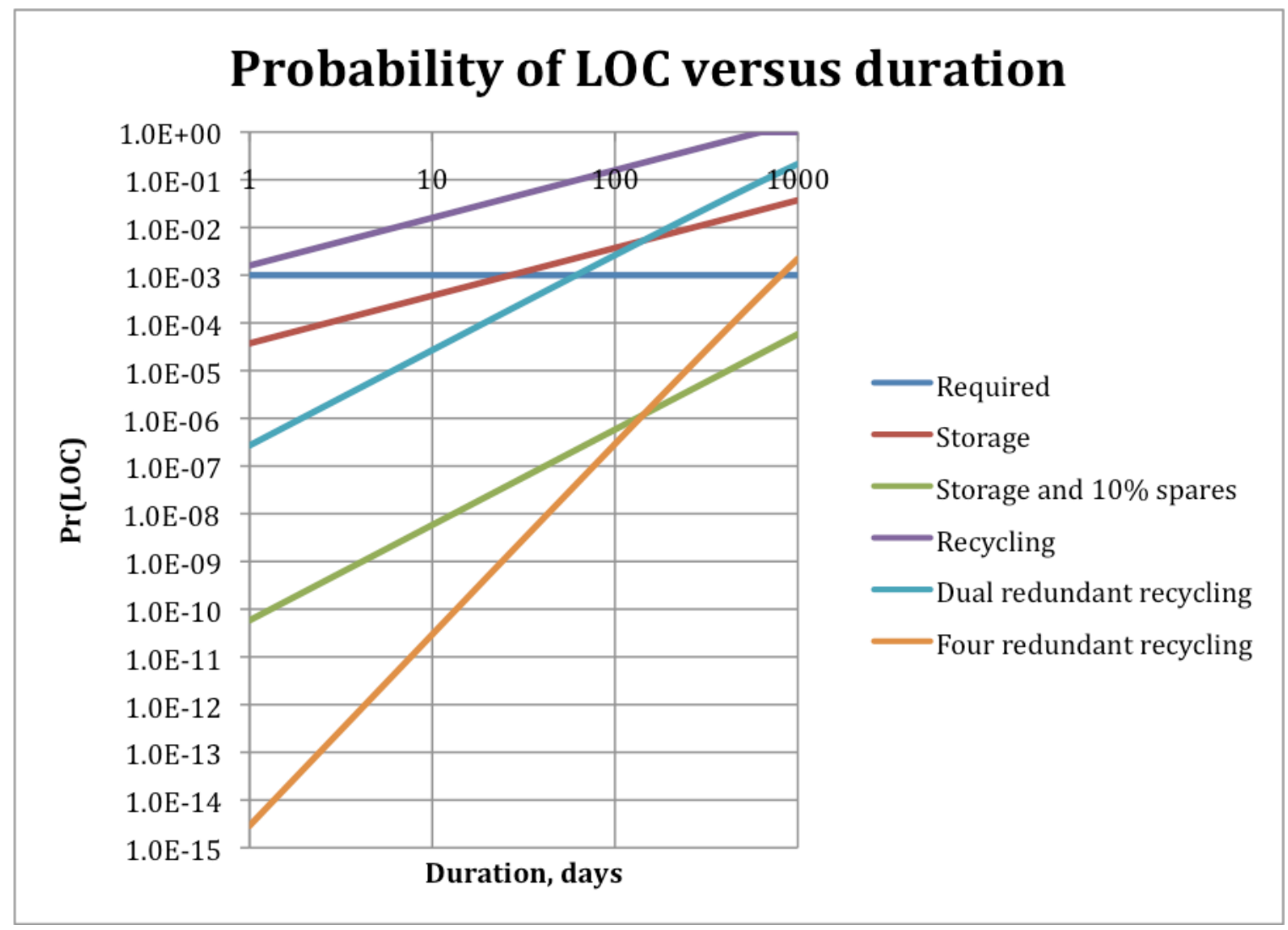

Figure 2. Storage and recycling $\operatorname{Pr}(\mathrm{LOC})$ 's.

The $\operatorname{Pr}(\mathrm{LOC})$ of a single recycling system, with spares that cut the failure rate by one order of magnitude, is 1.59 $* 10^{-3} * \mathrm{D}$, from Table 7 . The $\operatorname{Pr}(\mathrm{LOC})$ of a dual redundant, $\mathrm{N}=2$, recycling system is roughly the sum of the failure probabilities of the five pairs of subsystems. Allowing for the spares that cut the failure rate by ten, $\operatorname{Pr}(\mathrm{LOC})=(2.99$ $\left.* 10^{-4} * \mathrm{D}\right)^{2}+\left(2.74 * 10^{-4} * \mathrm{D}\right)^{2}+\left(2.10 * 10^{-4} * \mathrm{D}\right)^{2}+\left(4.39 * 10^{-4} * \mathrm{D}\right)^{2}+\left(3.71 * 10^{-4} * \mathrm{D}\right)^{2}=5.37 * 10^{-7} * \mathrm{D}^{2}$. (With dual redundancy, both redundant units must fail for the full system to fail. The probability that both redundant units will fail is the product of their individual failure probabilities.)

This calculation is correct if both the prime subsystems and the spare subsystems are run full time so must fail before life support is lost. It is much better to use cold spares, which have a negligible failure rate as long as they are not operating. The probability of a given number of failures with failed units being replaced by cold spares is given by the Poisson distribution, following calculations described in Jones, $2010 .{ }^{26}$ For one operating unit and one cold spare, the Poisson distribution shows that the above failure probability is reduced by half.

The recycling $\operatorname{Pr}(\mathrm{LOC})$ 's are plotted in Figure 2, for a single recycling system, $\mathrm{N}=2$ dual redundancy, and $\mathrm{N}=4$ redundancy. The Poisson distribution calculation is used for the redundant systems. Single recycling fails to meet the required $\operatorname{Pr}(\mathrm{LOC})$ of $10^{-3}$ even on the first day. $\mathrm{N}$ equals two redundancy meets the required $\operatorname{Pr}(\mathrm{LOC})$ only out to 
about 60 days, far short of the ESM breakeven date of 180 days. $\mathrm{N}$ equals four redundancy meets the required $\operatorname{Pr}(\mathrm{LOC})$ out to about 800 days, well beyond its ESM breakeven date of 300 days. The four redundant recycling system does have higher $\operatorname{Pr}(\mathrm{LOC})$ than storage with $10 \%$ spares at longer durations, but it meets the $\operatorname{Pr}(\mathrm{LOC})$ requirement and saves mass for mission durations between 300 and 800 days.

A triple redundancy system, $\mathrm{N}=3$, is of interest but not plotted. The ESM breakeven with storage and $10 \%$ spares occurs at about 240 days for $\mathrm{N}=3$ redundancy. $\mathrm{N}=3$ redundancy meets the required $\operatorname{Pr}(\mathrm{LOC})$ out to about 320 days.

Even though single string recycling has its ESM breakeven with storage at 120 days, its low reliability requires adding redundant systems that push the ESM recycling breakeven date further out. Using either storage with $10 \%$ spares or redundant recycling systems, we would use storage for missions from 1 to 240 days, triple redundant recycling from 240 to 320 days, quadruple redundant recycling from 320 to 800 days, and probably higher multiple recycling beyond 800 days.

This result for redundant recycling systems is disappointing. We would like recycling to breakeven sooner and save more ESM. The ability to use recycling is very sensitive to its ESM and failure rate. Current recycling systems appear to have inadequate reliability for deep space life support. Storage with spares easily achieves much better than the required $\operatorname{Pr}(\mathrm{LOC})$.

\section{Improved lower mass and failure rate recycling}

Suppose we could reduce the fixed ESM of recycling by a factor or two and reduce its failure rate per day by a factor of ten. The ESM of storage is $10.23 * \mathrm{D} \mathrm{kg} / \mathrm{CM}$ with ten percent spares. The ESM of recycling with $\mathrm{N}-1$ redundant non-operating spares was $1,095 \mathrm{~kg} / \mathrm{CM}+606 *(\mathrm{~N}-1) \mathrm{kg} / \mathrm{CM}+0.20 * \mathrm{D} \mathrm{kg} / \mathrm{CM}$. The fifty percent increase in fixed ESM for spares is included. If the fixed ESM is reduced by a factor of two, this becomes 548 $\mathrm{kg} / \mathrm{CM}+303 *(\mathrm{~N}-1) \mathrm{kg} / \mathrm{CM}+0.20 * \mathrm{D} \mathrm{kg} / \mathrm{CM}$. The ESM of storage with ten percent spares and of the improved recycling system alone and with dual redundancy is shown in Figure 3.

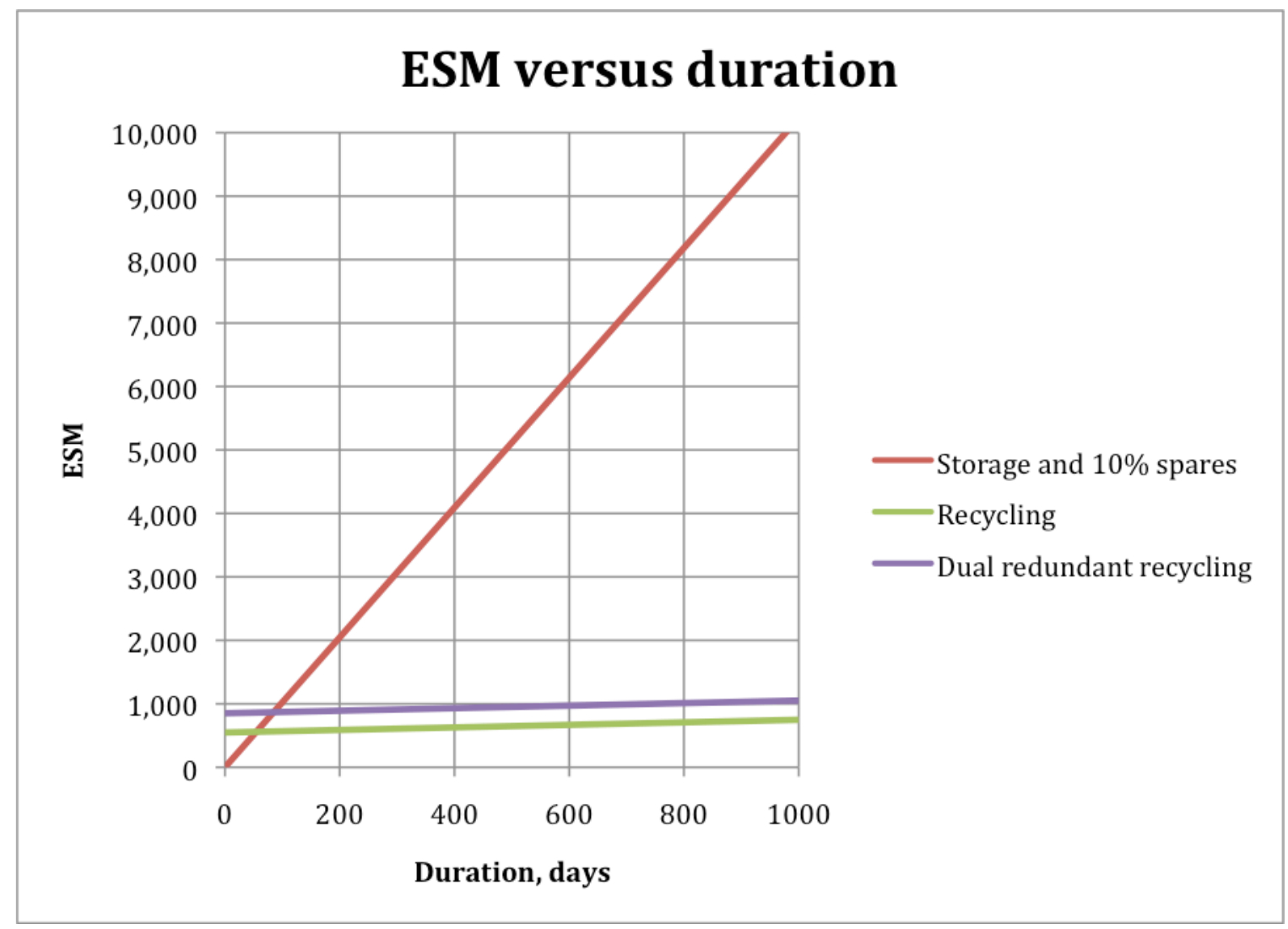

Figure 3. Storage and assumed improved recycling ESM. 
The recycling breakeven duration is about 60 days for a single recycling system and 100 days for dual redundancy.

The $\operatorname{Pr}(\mathrm{LOC})$ of storage with ten percent spares and of the assumed improved recycling system alone and with dual redundant systems is plotted in Figure 4.

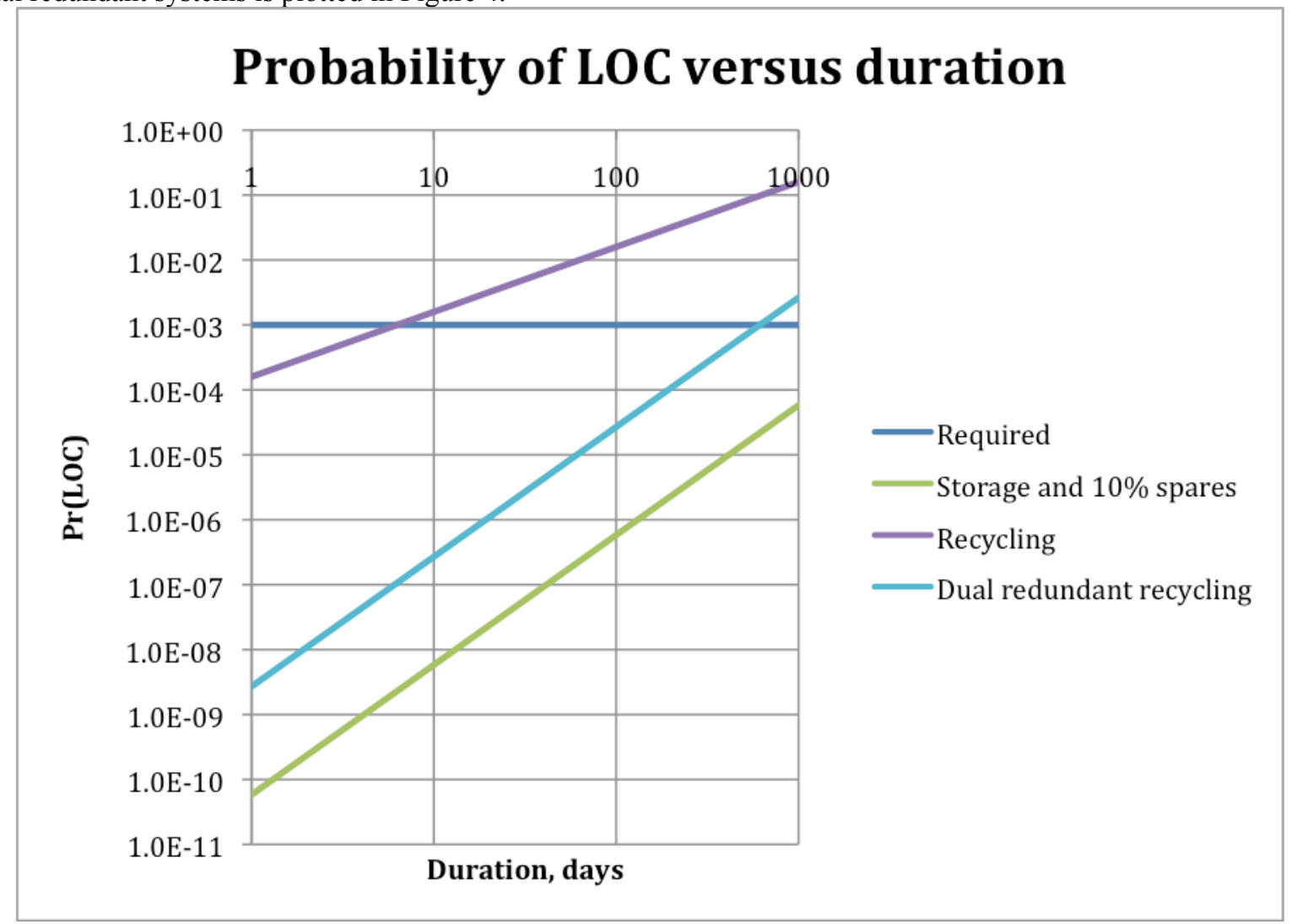

Figure 4. Storage and assumed improved recycling $\operatorname{Pr}(\mathrm{LOC})$.

The assumed improved recycling meets the required $\operatorname{Pr}(\mathrm{LOC})$ of less than $10^{-3}$ only for very short missions of a few days. Dual redundant improved recycling meets the required $\operatorname{Pr}(\mathrm{LOC})$ for missions as long as 600 days. Storage with ten percent spares has $\operatorname{Pr}(\mathrm{LOC})$ nearly two orders of magnitude better. With the assumed improvements, onehalf fixed recycling ESM and one-tenth recycling failure rates, a dual recycling system with one operating unit for each processor and one spare would save ESM and meet the required $\operatorname{Pr}(\mathrm{LOC})$ for missions from 100 to 600 days duration. This result shows that plausible improvements in recycling could make it the best system for long deep space missions.

\section{Combining storage and recycling}

Pure storage with ten percent spares can provide excellent reliability, more than reasonably required, but storage requires a very large mass for long missions. Recycling systems that would save most of the mass of storage have apparently inadequate reliability for deep space missions. Triple and quadruple redundant recycling is required to achieve a reasonable probability of loss of crew. Is it possible to combine storage and recycling to save mass over pure storage or gain better reliability than recycling?

\section{A. Effects of recycling processor failures}

Storage can be used to mitigate the effects of recycling failures, to forestall loss of the crew. The three necessary life support functions for survival are carbon dioxide removal, oxygen provision, and water provision. (Food is assumed available, dehydrated, and stored.) The five recycling processors perform carbon dioxide removal, carbon dioxide reduction, oxygen generation, water processing, and urine processing. If any one of these five key processors fails and its function is not otherwise supplied, loss of crew will occur. 
Consider the five key processors one by one. If carbon dioxide removal fails, carbon dioxide accumulates in the cabin atmosphere and the crew quickly succumbs. If carbon dioxide reduction fails, the product water is not available and the total water supply is ultimately depleted as its oxygen is converted to carbon dioxide. If oxygen generation from recycled water fails, oxygen cannot be provided to the crew. If the water processor fails, clean water runs out and all water ends as wastewater. Even if the urine processor alone fails, the water supply is depleted because all the recycled water becomes unrecoverable urine. If any one of the five processors fails, and its performance not replaced, loss of crew occurs.

\section{B. Mitigating recycling processor failures using storage}

If the prime carbon dioxide removal subsystem is a $4 \mathrm{BMS}$ and it fails, it must be replaced by a redundant processor or by stored $\mathrm{LiOH}$ to avoid loss of crew. Because normally the system recycles the carbon dioxide recovered by the 4BMS, the water and oxygen supplies will be impacted if the 4BMS fails. Loss of crew due to carbon dioxide accumulation will occur only if the 4BMS and all its backup systems fail.

If the carbon dioxide reduction subsystem fails, we lose its water production. The same water deficiency occurs if the 4BMS carbon dioxide removal system fails and we rely on LiOH. This water deficiency can be supplied by sufficient stored water. Then loss of crew will occur only if another water depleting failure occurs in addition to the carbon dioxide reduction system failure.

If the oxygen generation subsystem fails, it must be replaced by another one or by stored oxygen to avoid loss of crew. An alternative storage approach would provide oxygen and hydrogen. Operational flexibility could be improved by including a fuel cell to use hydrogen and oxygen produce water and electrical power. The oxygen and hydrogen could be in addition to or in place of stored water.

If the water processor and any redundant processors fail, all the crew's water must be supplied from storage. If all recycling processors fail, the crew will have no more than the stored water. Probably the carbon dioxide reduction product water can still be used for oxygen generation, without treatment by the water processor.

If the urine processor and its backups fail, a large amount of water is lost daily as unrecoverable urine. The amount of urine is variable, since it is obviously dependant on water consumption, and its nominal amount is a relatively small portion of the total requirement. It may be possible that the use of stored water and the operation of the recycling water processor can provide the crew with nearly the full amount of required water.

\section{Partial duration storage can improve reliability and extend missions}

Providing storage with spares to meet all requirements over the mission duration has high reliability but very high mass cost. Do we need sufficient storage to cover the full mission duration? Could we provide stored oxygen or water or $\mathrm{LiOH}$ for only a part of the mission duration?

At first, it seems we must provide storage for the full mission duration. $\operatorname{The} \operatorname{Pr}(\mathrm{LOC})$ of the assumed improved recycling system is $1.59 * 10^{-3} * \mathrm{D}$, which is 0.01 at 60 days. Suppose we added stored oxygen, water, and $\mathrm{LiOH}$ for half the mission duration, 30 days. The improved $\operatorname{Pr}(\mathrm{LOC})$ is one-half the original, 0.005 , since the recycling must operate without failure for the other 30 days. To reach the required $\operatorname{Pr}(\mathrm{LOC})$ of 0.001 , we must provide storage for 90 percent of the mission duration, 54 days. Providing storage for the full mission length would give much better reliability, only cost ten percent more storage, and would allow us to eliminate all recycling.

However, partial stores are more effective when combined with redundant recycling. For redundant systems, the $\operatorname{Pr}(\mathrm{LOC}) \sim \mathrm{D}^{\mathrm{N}}$, where $\mathrm{N}$ is the level of redundancy, typically 3 or 4 (see Section 7 for an example calculation). Again, suppose we added stored oxygen, water, and $\mathrm{LiOH}$ for half the mission duration. The $\operatorname{Pr}(\mathrm{LOC})$ for the other half of the mission that recycling would be needed is only one-eighth or one-sixteenth of the original $\operatorname{Pr}(\mathrm{LOC})$. To get a factor of ten reduction in $\operatorname{Pr}(\mathrm{LOC})$ with quadruple redundancy, stores would have to be provided for 56 percent of the mission. Adding partial stores to redundant recycling systems can improve their reliability significantly.

Alternately, partial mission duration storage can be used to extend the mission duration of a recycling system. The triple redundancy system has ESM breakeven at about 240 days and meets the required $\operatorname{Pr}($ LOC) out to about 320 days. If the mission duration is 350 days we can add 30 days of storage. The total ESM is $2,371 \mathrm{~kg}$ for recycling plus $307 \mathrm{~kg}$ for 30 days storage, 2,678 $\mathrm{kg}$ total. This is less than the ESM for quadruple recycling at 350 days, 2,983 kg. Providing partial storage also provides a useful dynamic buffer for down time and repairs.

\section{Adding 10 percent duration storage to recycling}

We consider the effects on ESM and $\operatorname{Pr}(\mathrm{LOC})$ of using redundant recycling and adding storage sufficient for ten percent of the mission duration. These mixed storage and recycling designs will be compared to the earlier designs, storage with $10 \%$ spares and to redundant recycling. 


\section{A. Recycling system with 10 percent storage ESM}

The ESM of the mixed storage and recycling life support design, with 10 percent of the mission duration supplied by storage, is $1,095 \mathrm{~kg} / \mathrm{CM}+0.20 * \mathrm{D} \mathrm{kg} / \mathrm{CM}$ plus $0.1 * 10.23 * \mathrm{D} \mathrm{kg} / \mathrm{CM}$ for 10 percent duration storage including $10 \%$ spares. The combined storage and recycling system ESM's are plotted in Figure 5.

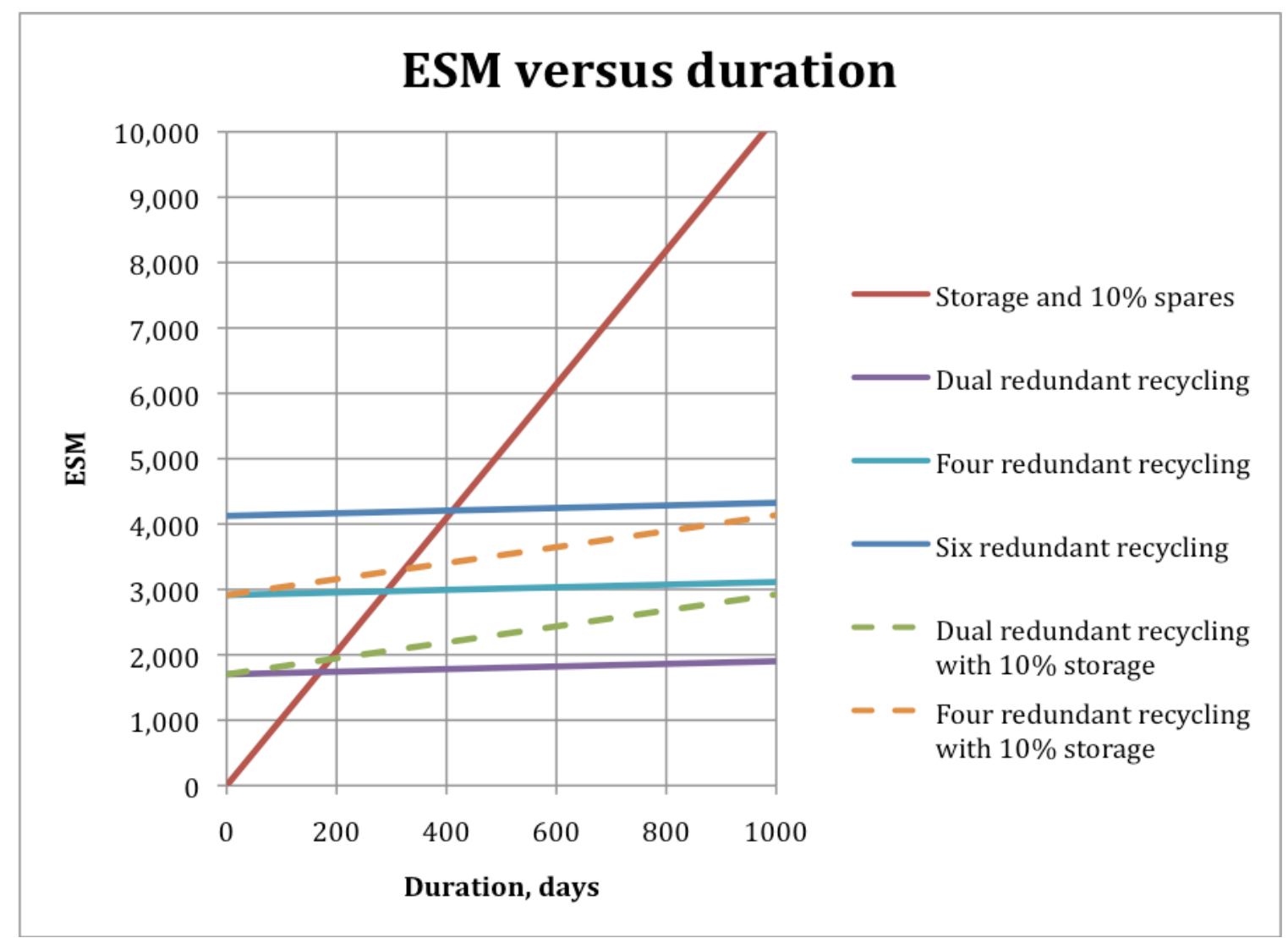

Figure 5. Combined recycling and 10\% storage system ESM.

The breakevens with pure storage occur for redundant recycling with $10 \%$ storage occur at somewhat later dates than without the added storage, 200 versus 180 days for $\mathrm{N}=2$ redundancy, and 340 versus 300 days for $\mathrm{N}=4$ redundancy.

\section{B. Recycling system with 10 percent storage $\operatorname{Pr}($ LOC)}

What is the failure probability of a redundant recycling system with ten percent added storage? With no added storage, loss of crew occurs as before, if all the redundant units of any subsystem fail during the mission. With the ten percent added storage, loss of crew occur if all the redundant units of any subsystem fail during the first 90 percent of the mission, or if all the redundant units fail during the last 10 percent of the mission and the storage also fails. This is complicated because both a processor and its specific backup storage must fail to cause loss of crew. If carbon dioxide removal fails and water storage fails, the crew is not impacted. Since storage can easily be made as reliable as needed using spares, we assume the 10 percent added storage does not fail. Then the reduced $\operatorname{Pr}(\mathrm{LOC})$ due to the 10 percent added storage is simply the probability that the redundant recycling system fails during the first 90 percent of the mission.

The recycling with 10 percent storage systems' $\operatorname{Pr}(\mathrm{LOC})$ 's are plotted in Figure 6. 


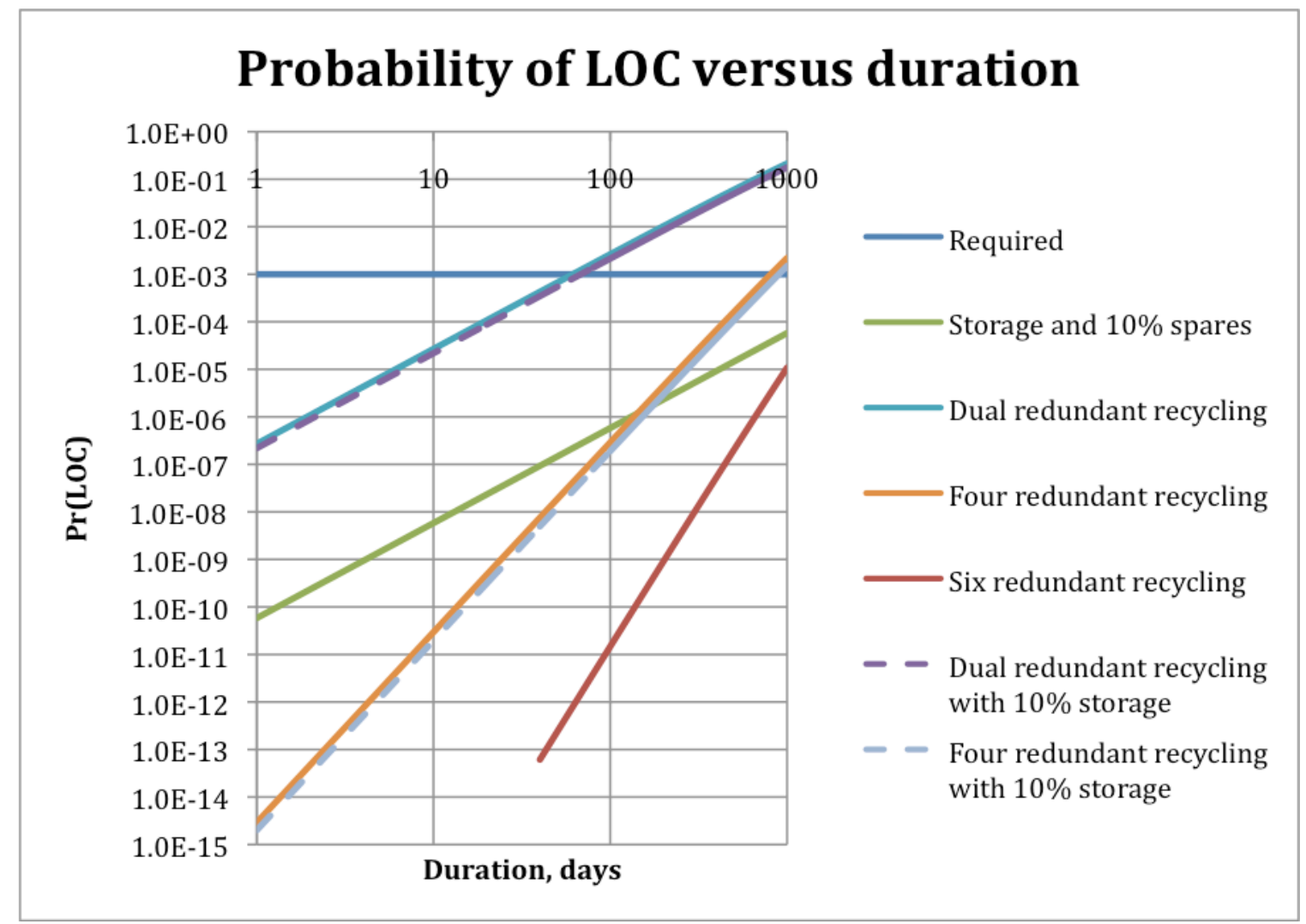

Figure 6. Combined recycling and 10\% storage system $\operatorname{Pr}(\mathrm{LOC})$.

The Pr(LOC)'s of N redundant recycling with 10 percent added storage seem very close to the Pr(LOC)'s without storage, but the logarithmic plot compresses the effect of the added storage. Four redundant recycling meets the required $\operatorname{Pr}(\mathrm{LOC})$ out to 800 days duration, while four redundant recycling with 10 percent storage meets the required $\operatorname{Pr}(\mathrm{LOC})$ out to 900 days duration.

The gains of added 10 percent storage are small compared to the gains of full redundant systems. $\mathrm{N}=6$ redundancy is shown in the ESM chart of Figure 5 and the $\operatorname{Pr}(\mathrm{LOC})$ chart of Figure 6 . At long mission durations of 800 to 1,000 days, $\mathrm{N}=6$ redundancy does not have much more ESM than four redundant recycling with $10 \%$ storage, but it has two orders of magnitude better $\operatorname{Pr}(\mathrm{LOC})$. Storage for part of the mission duration can improve $\operatorname{Pr}($ LOC $)$, but not very significantly.

\section{Partial water storage to reduce storage ESM}

Providing all the required life support materials for the full duration of the mission is the baseline full storage system. Above we considered providing all the materials for only a small portion of the mission duration. Next we consider providing some of the materials, but for the full mission duration.

Specifically, we consider providing the minimum survival water from storage and using recycling to provide the rest of the water requirement. This partial storage approach does not work for oxygen or carbon dioxide removal since the full oxygen supply and carbon dioxide removal capability are needed for crew survival.

The mixed storage and recycling system to be investigated has full oxygen storage, a full LiOH supply, and a partial water supply, all with ten percent spares for high reliability, and augmented with several water recycling processor systems to meet the full water requirement. Since the partial water supply is sufficient for crew survival, the $\operatorname{Pr}(\mathrm{LOC})$ of this partial water system is the same as that of full storage. The ESM is less than that of full storage by the net of water storage ESM reduction and water recycling ESM gain.

\section{A. Water requirements}

Table 8 shows the water requirements only, after Table 1, with the minimum survival water requirement and the estimated recycling products. 
Table 8. Survival and minimum water requirements and recycling.

\begin{tabular}{|l|c|l|r|l|r|}
\hline $\begin{array}{c}\text { Water } \\
\text { requirements }\end{array}$ & $\begin{array}{c}\mathrm{kg} / \mathrm{CM}- \\
\mathrm{d}\end{array}$ & \multicolumn{1}{|c|}{ Wastewater } & $\begin{array}{c}\mathrm{kg} / \mathrm{CM}- \\
\mathrm{d}\end{array}$ & \multicolumn{1}{|c|}{$\begin{array}{c}\text { Recycling } \\
\text { efficiencies }\end{array}$} & $\begin{array}{r}\text { Recycled } \\
\mathrm{kg} / \mathrm{CM}-\mathrm{d}\end{array}$ \\
\hline Survival water & 1.30 & \multicolumn{1}{|l|}{} & & \\
\hline Other crew water & 2.22 & $\begin{array}{l}\text { Respiration and perspiration } \\
\text { condensate }\end{array}$ & 2.28 & 0.99 & 2.26 \\
\hline Urine flush water & 0.50 & Urine and flush water & 2.00 & $0.90 * 0.99$ & 1.78 \\
\hline Wash water & 1.29 & Used wash water & 1.29 & 0.99 & 1.28 \\
\hline Total needs & 5.31 & Total waste & 5.57 & Recycled & 5.32 \\
\hline
\end{tabular}

Table 8 assumes that the food supply is dehydrated, which saves considerable launch mass but makes supplying the water requirements much more difficult. The crew must receive $1.15 \mathrm{~kg} / \mathrm{CM}$-d water to rehydrate the food plus $2.37 \mathrm{~kg} / \mathrm{CM}-\mathrm{d}$ drinking and food preparation water, a total of $3.52 \mathrm{~kg} / \mathrm{CM}-\mathrm{d}$. Of the $3.52 \mathrm{~kg} / \mathrm{CM}-\mathrm{d}$ supplied for crew consumption, $1.30 \mathrm{~kg} / \mathrm{CM}-\mathrm{d}$ is the survival minimum and $2.22 \mathrm{~kg} / \mathrm{CM}-\mathrm{d}$ is other crew water.

The total wastewater exceeds the water needs supplied due to the $0.35 \mathrm{~kg} / \mathrm{CM}-\mathrm{d}$ produced by the metabolism of food, less the $0.09 \mathrm{~kg} / \mathrm{CM}-\mathrm{d}$ in feces. $0.35-0.09=0.26=5.57-5.31$. If recycling is the only source of water it must be 95 percent efficient. $(5.31 / 5.57=0.953)$ This is just barely achieved with the assumed recycling efficiencies of 90 percent for urine and 99 percent for condensate and hygiene water. Current systems do not achieve these high assumed efficiencies.

Supplying fully hydrated food would make providing water much easier. The water supplied would need to be only $5.31-1.15=4.16 \mathrm{~kg} / \mathrm{CM}-\mathrm{d}$ and the recycling efficiency would need to be only $4.15 / 5.57=75$ percent. Even more significantly, the water stored in hydrated food would provide nearly all of the minimum survival water. The stored hydrated food is nearly the equivalent of a water storage tank holding all the survival water. Stored hydrated food could be used instead of a water storage tank.

\section{Water storage and water recycling design}

Four water delivery systems, each producing one quarter of the output, $5.32 / 4=1.33 \mathrm{~kg} / \mathrm{CM}-\mathrm{d}$ of water, will be used to produce the required water. One system uses storage and the other three perform recycling. Any one of the four sources is sufficient to supply the $1.33 \mathrm{~kg} / \mathrm{CM}-\mathrm{d}$ of survival water, so all four water sources must fail to cause loss of crew. Failures of all but one water supply source would cause inconvenience or loss of mission but not loss of crew. Additional recycling systems could be provided either to increase the water supply or as off-line spares to increase reliability.

\section{A. Water storage and recycling ESM}

We identify the ESM of a system with full oxygen and $\mathrm{LiOH}$ storage, one-quarter water storage, and threequarter water recycling. Table 9 shows the storage component ESM.

Table 9. Oxygen, $\mathrm{LiOH}$, and 1/4 water storage ESM.

\begin{tabular}{|l|r|}
\hline & $\mathrm{kg} / \mathrm{CM}-\mathrm{d}$ \\
\hline Oxygen & 0.84 \\
\hline Oxygen tankage & 0.34 \\
\hline Water & 1.33 \\
\hline Water tankage & 0.27 \\
\hline LiOH and packaging & 1.75 \\
\hline Total & 4.52 \\
\hline
\end{tabular}

The total ESM of Table 9 must be increased by ten percent to allow for the spares needed for high reliability, so the total storage ESM is $4.97 \mathrm{~kg} / \mathrm{CM}$-d. The water recycling system ESM is shown in Table 5 . The water processor has an ESM of $105 \mathrm{~kg} / \mathrm{CM}+0.13 \mathrm{~kg} / \mathrm{CM}-\mathrm{d}$. This must be increased by fifty percent to allow for the spares needed for high reliability, so the total ESM of three one-quarter capacity water processors is $1.5 * 0.75 *(105 \mathrm{~kg} / \mathrm{CM}+$ $0.13 \mathrm{~kg} / \mathrm{CM}-\mathrm{d}$ ) $=118 \mathrm{~kg} / \mathrm{CM}+0.15 \mathrm{~kg} / \mathrm{CM}$-d. (It is assumed that the water processor ESM scales linearly with capacity, so that a one quarter capacity processor has one quarter of the original processor ESM. The actual ESM of 
a one quarter capacity processor will probably be larger.) The urine processor has an ESM of $29 \mathrm{~kg} / \mathrm{CM}+0.06$ $\mathrm{kg} / \mathrm{CM}-\mathrm{d}$, which is also increased by fifty percent to allow for the spares, so the total urine processor is $1.5 *$ (26 $\mathrm{kg} / \mathrm{CM}+0.06 \mathrm{~kg} / \mathrm{CM}-\mathrm{d})=39 \mathrm{~kg} / \mathrm{CM}+0.09 \mathrm{~kg} / \mathrm{CM}-\mathrm{d}$. The total ESM for full oxygen and LiOH storage, onequarter water storage, and three-quarter water recycling is $157 \mathrm{~kg} / \mathrm{CM}+5.21 \mathrm{~kg} / \mathrm{CM}$-d. This ESM is plotted in Figure 7.

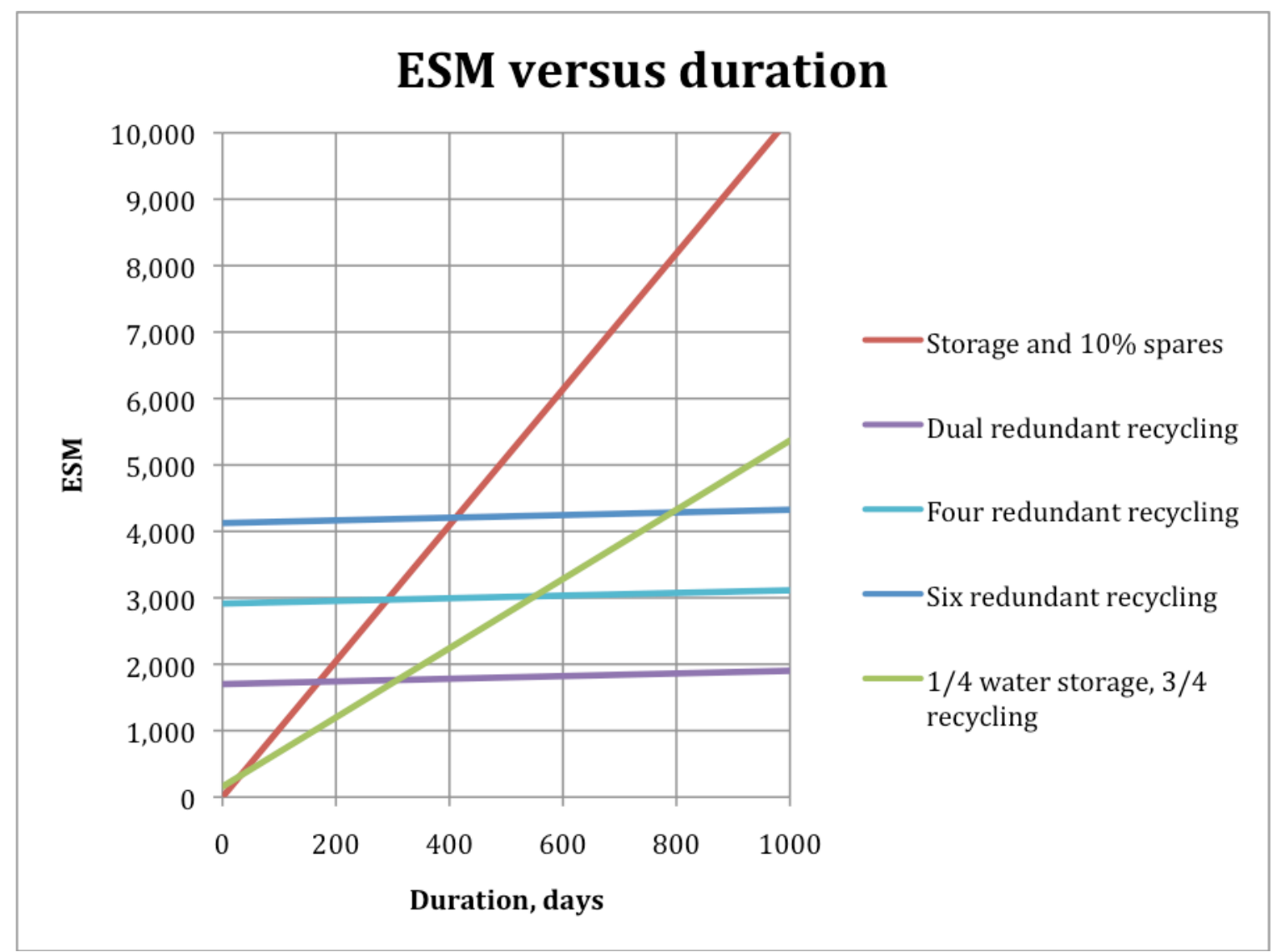

Figure 7. ESM versus mission duration.

The system with full oxygen and $\mathrm{LiOH}$ storage, one-quarter water storage, and three-quarter water recycling has about half the ESM of full storage. Both have $10 \%$ spares. The breakeven points with redundant recycling are at 320 days for $\mathrm{N}=2,580$ days for $\mathrm{N}=4$, and 800 days for $\mathrm{N}=6$.

\section{B. Water storage and recycling $\operatorname{Pr}(\mathrm{LOC})$}

The system with full oxygen and $\mathrm{LiOH}$ storage, one-quarter water storage, and three-quarter water recycling has the exact same $\operatorname{Pr}(\mathrm{LOC})$ as the full storage system. This $\operatorname{Pr}(\mathrm{LOC})$ is plotted in Figure 8. 


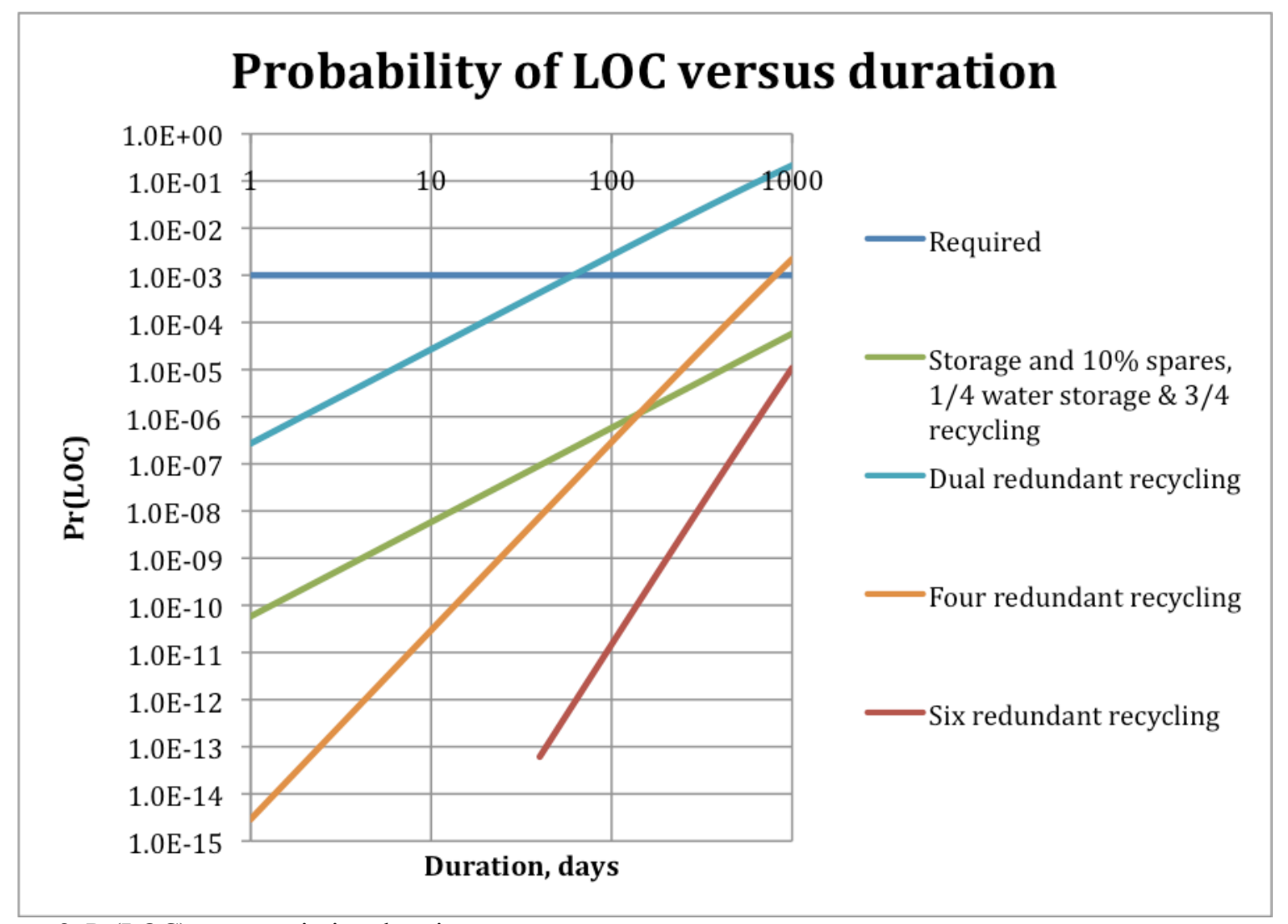

Figure $8 . \operatorname{Pr}($ LOC) versus mission duration.

The full storage system and the one-quarter water storage systems both have the same acceptable probability of loss of crew for mission durations beyond 1,000 days. The dual redundant recycling system meets the required $\operatorname{Pr}(\mathrm{LO})$ out to 60 days, the four redundant recycling system out to 300 days, and the six redundant recycling system out beyond 1,000 days.

A triple redundancy system, $\mathrm{N}=3$, has an ESM breakeven with the one-quarter water storage system at about 440 days for $\mathrm{N}=3$ redundancy. $\mathrm{N}=3$ redundancy meets the required $\operatorname{Pr}(\mathrm{LOC})$ out to about 320 days.

The one-quarter water storage system has minimum ESM out to 320 days. The dual redundant recycling has lowest ESM beyond 320 days but has too high $\operatorname{Pr}(\mathrm{LOC})$ beyond 60 days and so it is unusable where it saves mass. Eliminating the dual redundant recycling system, the one-quarter water storage system has lowest ESM out to 440 days. The triple redundant recycling system has lower ESM beyond 440 days but has too high $\operatorname{Pr}(\mathrm{LOC})$ beyond 320 days and so can not be used where it saves mass. Eliminating the triple redundant recycling system, the one-quarter water storage system has lowest ESM out to 580 days. The four redundant recycling has lower ESM beyond 580 days but has too high $\operatorname{Pr}(\mathrm{LOC})$ beyond 300 days and again can not be used. Eliminating the four redundant recycling system, the one-quarter water storage system has minimum ESM out to 800 days. Beyond that point the six redundant recycling system has lower ESM and sufficiently low $\operatorname{Pr}(\mathrm{LOC})$, even better than the full storage and onequarter water storage systems as designed.

\section{What are the best designs?}

The best design provides the required performance with the required reliability, at the minimum cost. Compared to the system with full oxygen and $\mathrm{LiOH}$ storage, one-quarter water storage, and three-quarter water recycling, none of the designs using redundant recycling without storage both save mass and meet the required probability of loss of crew for mission durations of less than 800 days, beyond which a six redundant recycling system is better, saving mass and exceeding the reliability requirement.

We found earlier that, when comparing multiply redundant recycling to a full storage system, that full storage was best for missions up to 240 days, and then triple, quadruple, and probably higher multiple recycling were better for longer durations beyond 240 days. The best designs are selected from the candidates compared. Since the one- 
quarter water storage system has less mass and the same probability of loss of crew as the full water storage system, one-quarter water storage can be better than systems that were better than full water storage.

We also noted earlier that, for improved recycling with one half lower ESM and one-tenth lower failure rates, multiple improved recycling systems would save ESM and meet the required $\operatorname{Pr}(\mathrm{LOC})$ for missions beyond 100 days duration, when compared to full storage. If multiple improved recycling was compared to the one-quarter water storage system, with roughly half the ESM of full storage, it would probably save ESM and meet the required $\operatorname{Pr}(\mathrm{LOC})$ for missions beyond 200 days duration.

Systems engineering is about trade-offs. Increasing reliability requires more mass and ESM, either more storage or added redundant recycling systems. The design choice between storage and recycling is especially difficult because the problems of each approach increase as mission duration increases. The mass of storage increases linearly with mission duration. The failure probability of $\mathrm{N}$ redundant recycling increases as mission duration to the Nth power. Recycling must achieve lower ESM and lower failure rates to dominate storage for deep space missions.

\section{Results summary}

We have always known:

1. Recycling is desirable on long missions to reduce life support mass.

2. Deep space missions will be long and so favor recycling.

3. Redundant recycling systems are needed to improve reliability.

4. Diverse redundancy helps prevent internal common cause failures.

We have recently realized:

1. Ultra reliable life support is needed in deep space since rapid resupply or crew return are not possible.

2. Stored material is much more reliable than recycling.

3. Deep space missions can use storage instead of or combined with recycling to increase reliability.

4. Ultra reliable recycling systems must be developed.

We now find:

1. Recycling systems do not have low enough mass and failure rates to be used to replace storage.

2. Material storage predominates in the lowest mass designs that meet reliability requirements.

3. High reliability storage must provide for all vital needs over the full mission duration.

4. The survival minimum of water is about one-fourth the total water requirement.

Storing only the water needed for survival can achieve the same low probability of loss of crew as full storage with about half the mass.

\section{Similar current results}

The recycling life support subsystem failure rates in Appendix A were computed using the schematics, parts lists, and component reliabilities in Yakut and Barker, $1968 .^{25}$ The recycling system architecture of Figure 1 and the subsystem technologies of Table 4 have not changed very much over the decades. It was assumed that the failure rates of basic components such as pumps, valves, heat exchangers, tanks, filters, etc. have not changed significantly. If components are now much more reliable, existing recycling systems would be more able to replace storage and save mass on long distant missions. This is unfortunately not true.

A paper by Lange and Anderson conducted a study similar to this and reached similar conclusions using projected failure rates for the ISS. ${ }^{27}$ They made quantitative assessments of ESM and reliability for a one year deep space mission. System reliability was increased by adding redundancy and spares. They found that achieving the reliability needed for deep-space missions will add substantially to life support mass and limit the use of recycling.

They found that as the allowed $\operatorname{Pr}(\mathrm{LOC})$ is reduced, the mass of recycling systems increases more rapidly than the mass of pure storage systems. This suggests that for the highest required reliabilities, pure storage systems would have the lowest mass. For a $\operatorname{Pr}(\mathrm{LOC})$ allocation to life support of 0.001 , the same as assumed in this study, they found the optimum system used partial storage, recovering water from humidity condensate and urine but using stored oxygen.

They conclude that high reliability requirements for deep space will substantially increase the life support system ESM and reduce the potential mass savings of recycling technologies. Since storage systems require excessive mass and recycling systems have insufficient reliability, they state "all of the architectures considered in this study are likely to be unacceptable for the 1-year deep-space mission scenario." 


\section{Conclusion}

The intended deliverable of this report was a flexible deep space life support system design approach that meets the material provision and reliability requirements with minimum launch mass. The selected design approach is to use storage or redundant recycling or a combination to achieve the required ultra reliability with minimum ESM. The best design achieves ultra reliability by using storage to provide all the materials necessary for crew survival over the mission duration and minimizes ESM by using recycling to provide the water required beyond the survival minimum. The design is flexible because it varies with the mission duration and can add recycling systems to enhance life support, even a full system for testing and reliability enhancement, and ultimately replace storage with recycling if it becomes sufficiently reliable.

The best deep space life support design uses a combined storage and recycling water system. Only one-quarter of the total minimal water requirement is necessary for crew survival, and it can be provided by high reliability storage. The other three quarters of the water requirement can be provided by three one-quarter capacity recycling systems, which could have diverse redundancy and are likely to operate throughout long missions but are not ultra reliable.

The partial storage approach does not work for the other recycling functions, since a partial oxygen supply or a partial carbon dioxide removal capability does not guarantee crew survival. But since water is two-thirds of the total storage, a partial water storage system does provide significant mass reductions compared to full storage.

For missions far from Earth, sending supplies or spare parts or returning quickly in the event of a life support failure is impossible. The crucial current design question for deep space life support is, "Can we implement recycling to save mass with ultra reliability or will we be forced to use storage for reliability?" The answer seems to be, "Recycling must be improved with lower mass and higher reliability before it can be the best design choice." Multiple redundant recycling processors can save mass over storage systems and can achieve sufficient reliability, but cannot easily do both at the same time. Ultra reliable life support is needed, but recycling equipment uses complex mechanical and chemical processors that are much less reliable than storage tanks. The low reliability of recycling systems largely prevents their use in deep space beyond the Earth-Moon system.

It was originally expected that recycling would dominate storage in the best design, at least for the shortest deep space missions, and that partial storage would be added for longer missions. As it turns out, current recycling systems do not seem to be sufficiently reliable to allow their use in deep space without storage back up. And providing less than full mission duration back up storage does not sufficiently improve reliability. It is not surprising that current recycling systems designed for ISS do not have sufficient reliability for deep space, since they were not required to have such high reliability. Current recycling systems can certainly save launch mass for long missions to LEO, the Moon, and anywhere in the Earth-Moon system, since quick crew return or resupply is possible and high reliability is not necessary.

\section{A. What must be done?}

With sufficient launch mass capability, human missions can begin to explore deep space in the near future, relying on life support largely using storage. The cost of Earth-supplied materials is very high. We have expected to reduce life support mass using advanced recycling. How can we do this?

Obviously, we must develop high reliability recycling systems. Current systems could be redesigned. Simpler more robust alternates could be developed. Automatic fault detection, isolation, and repair (FDIR) could be implemented. A spare parts and repair approach should be developed. In space manufacturing would be advantageous.

Next, we must measure and demonstrate high reliability using component bench tests and long duration full system test beds. To be reasonably sure a system will operate without failure for a year, several systems should be demonstrated to operate without failure for several years. Achieving ultra reliability is a long term program.

Then, operations on ISS and during actual missions are needed to confirm microgravity performance and to exercise repair approaches. We should fly combined storage and recycling systems until it can be shown that recycling systems have adequate reliability.

Finally, we should make mission changes to enhance crew safety. Stores and spare recycling parts could be preemplaced at mission destinations or turn around points. 


\section{Appendix A: Recycling life support subsystem failure rates}

The failure rates for the active recycling processors in the ISS life support system were computed using the schematics, parts lists, and component reliabilities in Yakut and Barker, $1968^{25}$ The processors are shown in Figure 1 and listed in Table 4 of the main report. A summary table for all the processors is given at the end of this appendix and is repeated in the main body of the report.

Table A 1. Carbon dioxide removal.

\begin{tabular}{|r|r|r|r|r|}
\hline $\begin{array}{c}\text { Carbon dioxide } \\
\text { removal }\end{array}$ & $\begin{array}{c}\text { Four Bed Molecular } \\
\text { Sieve (4BMS) }\end{array}$ & $\begin{array}{c}\text { Component failure rate } \\
\text { per day }\end{array}$ & $\begin{array}{c}\text { Number of each } \\
\text { component }\end{array}$ & $\begin{array}{c}\text { Total failure rate } \\
\text { per day }\end{array}$ \\
\hline Item & Component & & 4 & $4.80 \mathrm{E}-04$ \\
\hline 1 & Beds with heaters & $1.20 \mathrm{E}-04$ & 1 & $1.92 \mathrm{E}-04$ \\
\hline 2 & Blower & $1.92 \mathrm{E}-04$ & 1 & $2.40 \mathrm{E}-05$ \\
\hline 3 & CO2 accumulator & $2.40 \mathrm{E}-05$ & 3 & $7.20 \mathrm{E}-04$ \\
\hline 4 & Flow restrictor & $2.40 \mathrm{E}-04$ & 1 & $1.44 \mathrm{E}-04$ \\
\hline 5 & Heat exchanger & $1.44 \mathrm{E}-04$ & 1 & $4.20 \mathrm{E}-04$ \\
\hline 6 & Pump & $4.20 \mathrm{E}-04$ & 7 & $1.01 \mathrm{E}-03$ \\
\hline 7 & Valves & $1.44 \mathrm{E}-04$ & 18 & 0.0030 \\
\hline Totals & & & & \\
\hline
\end{tabular}

Table A 2. Sabatier carbon dioxide reduction.

\begin{tabular}{|c|c|c|c|c|}
\hline $\begin{array}{l}\text { Carbon dioxide } \\
\text { reduction }\end{array}$ & Sabatier & $\begin{array}{l}\text { Component failure rate } \\
\text { per day }\end{array}$ & $\begin{array}{l}\text { Number of each } \\
\text { component }\end{array}$ & $\begin{array}{c}\text { Total failure rate } \\
\text { per day }\end{array}$ \\
\hline Item & Component & & & \\
\hline 1 & $\mathrm{CO} 2$ tank & $1.00 \mathrm{E}-06$ & 1 & $1.00 \mathrm{E}-06$ \\
\hline 2 & Filters & $1.20 \mathrm{E}-04$ & 3 & $3.60 \mathrm{E}-04$ \\
\hline 3 & Flow restrictors & $2.40 \mathrm{E}-04$ & 2 & $4.80 \mathrm{E}-04$ \\
\hline 4 & $\mathrm{H} 2$ tank & $1.20 \mathrm{E}-05$ & 1 & $1.20 \mathrm{E}-05$ \\
\hline 5 & $\mathrm{H} 2 \mathrm{O} \operatorname{tank}$ & $2.40 \mathrm{E}-07$ & 1 & $2.40 \mathrm{E}-07$ \\
\hline 6 & $\begin{array}{r}\text { Liquid/gas } \\
\text { separator }\end{array}$ & $4.00 \mathrm{E}-04$ & 1 & $4.00 \mathrm{E}-04$ \\
\hline 7 & Sabatier reactor & $4.80 \mathrm{E}-04$ & 1 & $4.80 \mathrm{E}-04$ \\
\hline 8 & Valves & $1.44 \mathrm{E}-04$ & 7 & $1.01 \mathrm{E}-03$ \\
\hline Totals & & & 17 & 0.0027 \\
\hline
\end{tabular}

Table A 3. Electrolysis oxygen generation.

\begin{tabular}{|r|r|r|r|r|}
\hline $\begin{array}{c}\text { Oxygen } \\
\text { generation }\end{array}$ & $\begin{array}{c}\text { Solid Polymer Water } \\
\text { Electrolysis (SPWE) }\end{array}$ & $\begin{array}{c}\text { Component failure } \\
\text { rate per day }\end{array}$ & $\begin{array}{c}\text { Number of each } \\
\text { component }\end{array}$ & $\begin{array}{c}\text { Total failure rate } \\
\text { per day }\end{array}$ \\
\hline Item & Component & & 1 & $2.40 \mathrm{E}-04$ \\
\hline 1 & Electrolysis unit & $2.40 \mathrm{E}-04$ & 2 & $4.80 \mathrm{E}-04$ \\
\hline 2 & Flow restrictors & $2.40 \mathrm{E}-04$ & 1 & $1.20 \mathrm{E}-05$ \\
\hline 3 & H2 tank & $1.20 \mathrm{E}-05$ & 1 & $1.00 \mathrm{E}-06$ \\
\hline 4 & O2 tank & $1.00 \mathrm{E}-06$ & 1 & $2.40 \mathrm{E}-04$ \\
\hline 5 & Power supply & $2.40 \mathrm{E}-04$ & 2 & $4.80 \mathrm{E}-04$ \\
\hline 6 & Pressure controllers & $2.40 \mathrm{E}-04$ & 2 & $2.87 \mathrm{E}-04$ \\
\hline 7 & Valves & $1.44 \mathrm{E}-04$ & 1 & $3.60 \mathrm{E}-04$ \\
\hline 8 & Water pump & $3.60 \mathrm{E}-04$ & 11 & 0.0021 \\
\hline Totals & & & &
\end{tabular}


Table A 4. Multifiltration water processor.

\begin{tabular}{|c|c|c|c|c|}
\hline $\begin{array}{r}\text { Water } \\
\text { processing }\end{array}$ & Multifiltration & $\begin{array}{r}\text { Component failure rate } \\
\text { per day }\end{array}$ & $\begin{array}{r}\text { Number of each } \\
\text { component } \\
\end{array}$ & $\begin{array}{r}\text { Total failure rate } \\
\text { per day }\end{array}$ \\
\hline Item & Component & & & \\
\hline 1 & Charcoal filters & $3.60 \mathrm{E}-05$ & 2 & $7.20 \mathrm{E}-05$ \\
\hline 2 & Chloride dispenser & $1.20 \mathrm{E}-04$ & 1 & $1.20 \mathrm{E}-04$ \\
\hline 3 & Filters & $3.60 \mathrm{E}-05$ & 2 & $7.20 \mathrm{E}-05$ \\
\hline 4 & Flow restrictors & $2.40 \mathrm{E}-04$ & 4 & $9.60 \mathrm{E}-04$ \\
\hline 5 & Membrane & $3.60 \mathrm{E}-05$ & 1 & $3.60 \mathrm{E}-05$ \\
\hline 6 & Pumps & $3.60 \mathrm{E}-04$ & 2 & $7.20 \mathrm{E}-04$ \\
\hline 7 & Resin bed & $3.60 \mathrm{E}-05$ & 1 & $3.60 \mathrm{E}-05$ \\
\hline 8 & Sensors & $2.40 \mathrm{E}-04$ & 4 & $9.60 \mathrm{E}-04$ \\
\hline 9 & $\begin{array}{r}\text { Solenoid flow } \\
\text { control } \\
\end{array}$ & $2.40 \mathrm{E}-04$ & 1 & $2.40 \mathrm{E}-04$ \\
\hline 10 & UV light & $6.00 \mathrm{E}-04$ & 1 & $6.00 \mathrm{E}-04$ \\
\hline 11 & Valves & $1.44 \mathrm{E}-04$ & 4 & $5.75 \mathrm{E}-04$ \\
\hline 12 & Water tanks & $2.40 \mathrm{E}-07$ & 2 & $4.80 \mathrm{E}-07$ \\
\hline Totals & & & 25 & 0.0044 \\
\hline
\end{tabular}

Table A 5. VCD urine processor.

\begin{tabular}{|c|c|c|c|c|}
\hline $\begin{array}{r}\text { Urine } \\
\text { processing }\end{array}$ & $\begin{array}{l}\text { Vapor Compression } \\
\text { Distillation (VCD) }\end{array}$ & $\begin{array}{r}\text { Component failure rate } \\
\text { per day }\end{array}$ & $\begin{array}{r}\text { Number of each } \\
\text { component }\end{array}$ & $\begin{array}{r}\text { Total failure rate } \\
\text { per day }\end{array}$ \\
\hline Item & Component & & & \\
\hline 1 & Charcoal beds & $3.60 \mathrm{E}-05$ & 2 & $7.20 \mathrm{E}-05$ \\
\hline 2 & Compressor & $3.60 \mathrm{E}-04$ & 1 & $3.60 \mathrm{E}-04$ \\
\hline 3 & Condensor & $4.00 \mathrm{E}-04$ & 1 & $4.00 \mathrm{E}-04$ \\
\hline 4 & Conductivity probe & $2.40 \mathrm{E}-04$ & 1 & $2.40 \mathrm{E}-04$ \\
\hline 5 & Evaporator & $2.40 \mathrm{E}-04$ & 1 & $2.40 \mathrm{E}-04$ \\
\hline 6 & Fan & $1.92 \mathrm{E}-04$ & 1 & $1.92 \mathrm{E}-04$ \\
\hline 7 & Filter & $3.60 \mathrm{E}-05$ & 1 & $3.60 \mathrm{E}-05$ \\
\hline 8 & Flow restrictors & $2.40 \mathrm{E}-04$ & 3 & $7.20 \mathrm{E}-04$ \\
\hline 9 & Heat exchanger & $1.44 \mathrm{E}-04$ & 1 & $1.44 \mathrm{E}-04$ \\
\hline 10 & Pump & $3.60 \mathrm{E}-04$ & 1 & $3.60 \mathrm{E}-04$ \\
\hline 11 & Resin bed & $3.60 \mathrm{E}-05$ & 1 & $3.60 \mathrm{E}-05$ \\
\hline 12 & Sensors & $2.40 \mathrm{E}-04$ & 2 & $4.80 \mathrm{E}-04$ \\
\hline 13 & Valves & $1.44 \mathrm{E}-04$ & 3 & $4.31 \mathrm{E}-04$ \\
\hline 14 & Water tanks & $2.40 \mathrm{E}-07$ & 4 & $9.60 \mathrm{E}-07$ \\
\hline Totals & & & 23 & 0.0037 \\
\hline
\end{tabular}

Table A 6 gives the five processor failure rates per day from the above tables. 
Table A 6. All recycling processor failure rates per day, MTBF, and $\operatorname{Pr}($ fail).

\begin{tabular}{|c|c|c|c|c|c|c|}
\hline Function & Processor & $\begin{array}{l}\text { Failure rate } \\
\text { per day }\end{array}$ & $\begin{array}{l}\text { MTBF, } \\
\text { days }\end{array}$ & $\begin{array}{l}\text { One-tenth } \\
\text { failure rate }\end{array}$ & $\begin{array}{c}\text { Ten } \\
\text { times } \\
\text { MTBF, } \\
\text { days } \\
\end{array}$ & $\begin{array}{l}\operatorname{Pr}(\text { fail }) \text { in } \\
1,000 \text { days }\end{array}$ \\
\hline $\begin{array}{l}\text { Carbon dioxide } \\
\text { removal }\end{array}$ & $\begin{array}{l}\text { Four Bed Molecular } \\
\text { Sieve (4BMS) }\end{array}$ & $2.99 \mathrm{E}-03$ & 335 & $2.99 \mathrm{E}-04$ & 3,349 & 0.299 \\
\hline $\begin{array}{l}\text { Carbon dioxide } \\
\text { reduction }\end{array}$ & Sabatier & $2.74 \mathrm{E}-03$ & 365 & $2.74 \mathrm{E}-04$ & 3,651 & 0.274 \\
\hline Oxygen generation & $\begin{array}{l}\text { Solid Polymer } \\
\text { Water Electrolysis } \\
\text { (SPWE) }\end{array}$ & $2.10 \mathrm{E}-03$ & 476 & $2.10 \mathrm{E}-04$ & 4,761 & 0.210 \\
\hline Water processing & Multifiltration & $4.39 \mathrm{E}-03$ & 228 & $4.39 \mathrm{E}-04$ & 2,277 & 0.439 \\
\hline Urine processing & $\begin{array}{l}\text { Vapor Compression } \\
\text { Distillation (VCD) } \\
\end{array}$ & $3.71 \mathrm{E}-03$ & 269 & $3.71 \mathrm{E}-04$ & 2,694 & 0.371 \\
\hline & Totals & $1.59 \mathrm{E}-02$ & 63 & $1.59 \mathrm{E}-03$ & 628 & 1.000 \\
\hline
\end{tabular}

The Mean Time Before Failure (MTBF) is the inverse of the failure rate. The individual processor failure rates are roughly 2 to 4 per 1,000 days, so the MTBF's are 250 to 500 days. Many failures will occur during a 1,000 day mission. The overall life support system failure rate is 1 per 1,000 days, with a corresponding MTBF of 63 days.

Spare parts will be provided for key functional units and for valves, pumps, fans, and sensors that are more likely to fail. It is assumed that nine out of ten failures will be repaired, so that the rate of unrepairable failures that would render the recycling system inoperative is one-tenth of the component failure rate. The one-tenth failure rate and the corresponding ten times greater MTBF are shown in Table A 6. The corresponding probabilities of failure, $\operatorname{Pr}($ fail), in a 1,000 day mission are also shown and are quite large, 21 to 44 percent. It is nearly certain that an all recycling system will fail during a 1,000 day mission. Table A.6 is repeated in the main report as Table 7.

\section{Appendix B: Exact failure probability calculations}

The main body of this paper assumes that failure rates are constant and small. This allows the approximation that the probability of failure over the mission period is equal to the failure rate per day times the mission duration in days. This approximation overestimates the probability of failure when the exact computed probability of failure is more than a few percent. For example, the $\operatorname{Pr}(\mathrm{LOC})$ 's in Table 7 are 10 to 20 percent too high.

The failure rate, $\lambda$, is the number of times a component or system is expected to fail per unit time. A constant failure rate is nearly always assumed to simplify reliability analysis. Some components have a failure rate that decreases with time at first, remains constant during a period of useful life, and finally increases due to wear out, following the classic "bathtub curve." The initially decreasing failure rate is due to burn-in and early failure of defective components. The constant failures during useful life are random events. The terminal increasing failure rate can be caused by wear out or aging.

The reliability, $\mathrm{R}(\mathrm{t})$, is the probability that a system does not fail before time $t$. If the failure rate, $\lambda$, is a constant, the reliability, $R(t)$, is an exponential function.

$R(t)=\exp (-\lambda t)$

The failure probability, $\mathrm{F}(\mathrm{t})$, is the probability that a system does fail before time $\mathrm{t}$.

$F(t)=1-R(t)=1-\exp (-\lambda t)$

For very small values of $\lambda \mathrm{t}$, a Taylor series expansion about zero yields the following approximation,

$$
\begin{aligned}
& \mathrm{F}(\mathrm{t})=1-\exp (-\lambda \mathrm{t})=1-\left[1+(-\lambda \mathrm{t})+(-\lambda \mathrm{t})^{2} / 2 !+(-\lambda \mathrm{t})^{3} / 3 !+\ldots\right] \\
& \mathrm{F}(\mathrm{t}) \sim \lambda \mathrm{t}
\end{aligned}
$$


The error is less than the term $(\lambda t)^{2} / 2$, or one-half the approximate $F(t)$ squared. If the approximate $F(t)$ is 0.1 , or 10 percent, the error is less than 0.005 , or one half of one percent. $($ For $F(t)=1-\exp (-0.1)$, the approximate $F(t)=$ 0.1 and the exact $F(t)=0.095$.)

As mentioned, the $\operatorname{Pr}(\mathrm{LOC})$ 's in Table 7 are 10 to 20 percent too high. Table B1 shows the approximate and exact $\operatorname{Pr}(\mathrm{LOC})$ 's for 1,000 days.

Table B1. Approximate and exact $\operatorname{Pr}(\mathrm{LOC})$ 's for 1,000 days.

\begin{tabular}{|l|l|r|r|r|r|}
\hline \multicolumn{1}{|c|}{ Function } & \multicolumn{1}{|c|}{$\begin{array}{c}\text { LOC one } \\
\text { tenth } \\
\text { failure rate }\end{array}$} & $\begin{array}{c}\text { Approximate } \\
\operatorname{Pr}(\text { LOC) in } \\
1,000 \text { days }\end{array}$ & $\begin{array}{c}\text { Exact } \\
\operatorname{Pr}(\text { LOC) in } \\
1,000 \text { days }\end{array}$ & $\begin{array}{c}\text { Difference between } \\
\text { Approximate and Exact } \\
\operatorname{Pr}(\text { LOC) in 1,000 days }\end{array}$ \\
\hline $\begin{array}{l}\text { Carbon dioxide } \\
\text { removal }\end{array}$ & $\begin{array}{l}\text { Four Bed Molecular } \\
\text { Sieve (4BMS) }\end{array}$ & $2.99 \mathrm{E}-04$ & 0.299 & 0.258 & 0.041 \\
\hline $\begin{array}{l}\text { Carbon dioxide } \\
\text { reduction }\end{array}$ & Sabatier & $2.74 \mathrm{E}-04$ & 0.274 & 0.240 & 0.034 \\
\hline $\begin{array}{l}\text { Oxygen } \\
\text { generation }\end{array}$ & $\begin{array}{l}\text { Solid Polymer Water } \\
\text { Electrolysis (SPWE) }\end{array}$ & $2.10 \mathrm{E}-04$ & 0.210 & 0.189 & 0.021 \\
\hline $\begin{array}{l}\text { Water } \\
\text { processing }\end{array}$ & Multifiltration & $4.39 \mathrm{E}-04$ & 0.439 & 0.355 & 0.084 \\
\hline $\begin{array}{l}\text { Urine } \\
\text { processing }\end{array}$ & $\begin{array}{l}\text { Vapor Compression } \\
\text { Distillation (VCD) }\end{array}$ & $3.71 \mathrm{E}-04$ & 0.371 & 0.310 & 0.061 \\
\hline & Totals & $1.59 \mathrm{E}-03$ & 0.860 & 0.796 & 0.064 \\
\hline
\end{tabular}

The line plots of $\operatorname{Pr}(\mathrm{LOC})$ versus duration shown in Figures 2, 4, 6, and 8 in some cases go to less than 0.1 , so the approximation for small values of $\lambda t$ does not apply. The exact $\operatorname{Pr}(\mathrm{LOC})$ curve would increase toward 1.0 less rapidly. However, we are attempting to develop designs with a required $\operatorname{Pr}(\mathrm{LOC})$ less than 0.001 , so the use of the approximation does not affect the design results.

In general, the reason that the approximation $\mathrm{F}(\mathrm{t}) \sim \lambda \mathrm{t}$ is widely used is that systems are usually designed to have very low failure probabilities. The approximation for very small values of $\lambda t$ applies. 


\section{References}

${ }^{1}$ Lange, K. "Water Architectures: SIMA 2010 Study,” Joint LSHS Water/Project Analysis Telecon, November 29, 2010.

${ }^{2}$ Swickrath, M. J., "Parametric Analysis of Life Support Systems for Future Space Exploration Missions," AIAA-20115039, 41st International Conference on Environmental Systems (ICES), 2011.

${ }^{3}$ Jones, H., "Breakeven mission durations for physicochemical recycling to replace direct supply life support," SAE 200701-3221, 37th International Conference on Environmental Systems (ICES), 2007.

${ }^{4}$ Human Exploration Framework Team (HEFT), Phase I Closeout, NASA Steering Council, September 2, 2010.

${ }^{5}$ Reed, R. D., and G. R. Coulter, "Physiology of Spaceflight," in W. K. Larson, and L. K. Pranke, eds., Human Spaceflight: Mission Analysis and Design, McGraw-Hill, New York, undated (appeared in 2000).

${ }^{6}$ Wieland, P. O., Designing for Human Presence in Space: An Introduction to Environmental Control and Life Support Systems, NASA Reference Publication RP-1324, 1994.

7 Jones, H., and Kliss, M., "Developing an Advanced Life Support System for the Flexible Path into Deep Space," AIAA 2010-6036, 40th International Conference on Environmental Systems, (ICES), 2010.

${ }^{8}$ Jones, H., and Kliss, M., "Air and Water System (AWS) Design and Technology Selection for the Vision for Space Exploration," SAE Technical Paper No. 2005-01-2810, 33rd International Conference on Environmental Systems, (ICES),2005.

${ }^{9}$ NASA Exploration Atmospheres Working Group, "Recommendations for Exploration Spacecraft Internal Atmospheres: The Final Report of the NASA Exploration Atmospheres Working Group," NASA/TP-2010-216134, National Aeronautics and Space Administration, Houston, TX, October, 2007.

${ }^{10}$ Human Systems Integration Requirements (HSIR), CxP 70024, NASA Constellation Program, September 15, 2006.

${ }^{11}$ Duffield, B. editor, "Exploration Life Support Baseline Values and Assumptions Document," JSC-64367 Rev B., National Aeronautics and Space Administration, February 26, 2010

${ }^{12}$ Cronyn, P.D., Watkins, S. and Alexander, D.J. "Chronic Exposure to Moderately Elevated CO2 during Long-Duration Space Flight", NASA/TP-2012-217358, National Aeronautics and Space Administration, March 12, 2012.

${ }^{13}$ Jones, H., "Lunar Base Life Support Failure Analysis and Simulation," SAE Technical Paper No. 2009-01-2482, Society of Automotive Engineers, Warrendale, PA, 39th International Conference on Environmental Systems, (ICES), 2009.

${ }^{14}$ Piantadosi, C.A. 2003. The Biology of Human Survival. Oxford University Press. New York.

${ }^{15}$ Sawka, M. N., Cheuvront, S. N., Carter, R., "Human Water Needs," U.S. Army Research Institute of Environmental Medicine, June, 2005. Nutrition Reviews, Volume 63, No. 6. Pages S30-S39. Can be found at http://www.dtic.mil/cgibin/GetTRDoc?AD=ADA435156\&Location=U2\&doc=GetTRDoc.pdf

${ }^{16}$ Initial Lunar Outpost (ILO) Life Support System Baseline Design and Systems Assessment, 90-SAS-R-05, NASA ARC, September 16, 1991.

${ }^{17}$ Eckart, P., Spaceflight Life Support and Biospherics, Kluwer Academic, Dordrecht, 1996.

${ }^{18}$ Diamant and W. R. Humphries, "Past and Present Environmental Control and Life Support Systems on Manned Spacecraft," SAE Technical Paper No. 901210, 20th International Conference on Environmental Systems, (ICES) 1990.

${ }^{19}$ Carasquillo, R. L., and D. Bertotto, "ECLSS Design for the International Space Station Nodes 2 \& 3," SAE Technical Paper No. 1999-01-2146, Society of Automotive Engineers, Warrendale, PA, 29th International Conference on Environmental Systems, (ICES) 1999

${ }^{20}$ Bagdigian. R. M., and K. Y. Ogle, "International Space Station Node 3 Environmental Control and Life Support System Status," SAE Technical Paper No. 2001-01-2387, 31st International Conference on Environmental Systems (ICES), 2001.

${ }^{21}$ Carasquillo, R. L., R. M. Bagdigian, J. F. Lewis, and J. L. Perry, "Evolution of the Baseline ISS ECLSS Technologies The Next Logical Steps," SAE Technical Paper No. 2004-01-2385, 34th International Conference on Environmental Systems (ICES), 2004.

${ }^{22}$ Carrasquillo, R. L., J. L., Reuter, and C. L. Philistine, "Summary of Resources for the International Space Station Environmental Control and Life Support System," 27th International Conference on Environmental Systems, (ICES) 972332, 1997.

${ }^{23}$ Jones, H. W., "Equivalent Mass versus Life Cycle Cost for Life Support Technology Selection," SAE Technical Paper No. 2003-01-2635, 33rd International Conference on Environmental Systems (ICES), 2003.

${ }^{24}$ Jones, H., "Ultra Reliable Space Life Support Systems," SAE Technical Paper No. 2008-01-2160, 38th International Conference on Environmental Systems (ICES), 2008.

${ }^{25}$ Yakut, M. M, and Barker, R. S., "Parametric study of manned life support systems, Volume 2 - Parametric relations and scaling law", Final report, McDonnell Douglas CR 3283, Jul. 1967- Aug. 1968.

${ }^{26}$ Jones, H., "Life Support Dependability for Long Space Missions," AIAA-2010-6287, 40th International Conference on Environmental Systems (ICES), 2010.

${ }^{27}$ Lange, K. E., and Anderson, M. S., "Reliability Impacts in Life Support Architecture and Technology Selection," to be presented, 42nd International Conference on Environmental Systems (ICES), 2012. 